\title{
The Wright Brothers: First Aeronautical Engineers and Test Pilots
}

\author{
F. E. C. Culick \\ California Institute of Technology, Pasadena, California 91125
}

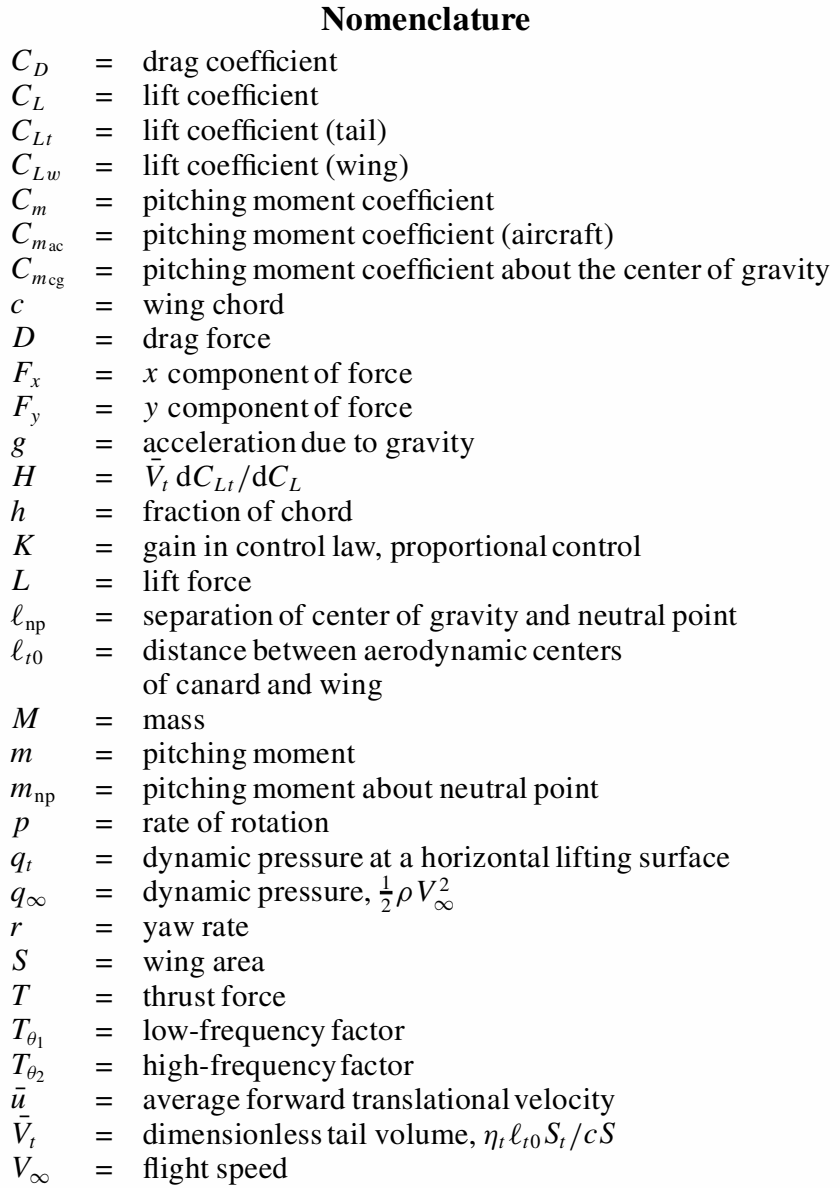

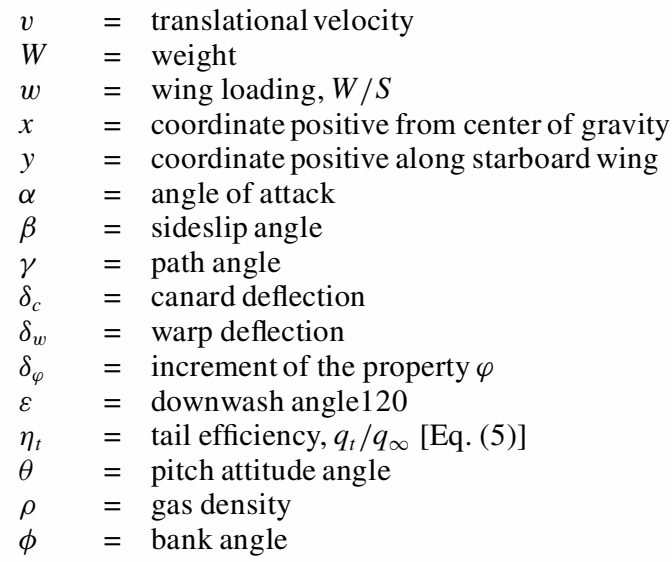

\section{Subscripts and Superscripts}

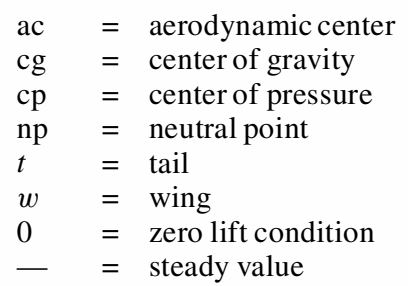

Q IR George Cayley invented the conventional configuration of $\checkmark$ the airplane at the turn of the 19th century. Otto Lilienthal realized that building a successful aircraft meant learning how to fly; he became the first hang glider pilot and also the first flight fatality in 1896. Beginning in the late 1890s, the Wright Brothers absorbed all that was known in aeronautics before them, then added their own

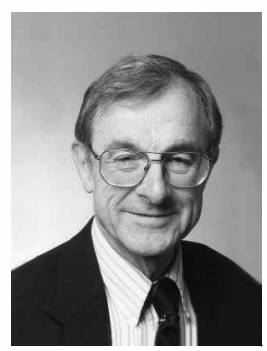

Fred E.C. Culick joined the faculty of the California Institute of Technology after receiving his Ph.D in Aeronautics and Astronautics from the Massachusetts Institute of Technology in 1961. He is currently Richard L. and Dorothy M. Hayman Professor of Mechanical Engineering and Professor of Jet Propulsion. Dr. Culick's Ph.D. dissertation treated combustion instabilities in liquid rockets. Much of his research since has been concerned with problems of unsteady motions in combustion chambers generally. He began working on solid rocket combustion instabilities in 1965; since 1979 he has been addressing the problem in airbreathing systems, with recent emphasis on feedback control applied to combustion systems, and measurements of combustion dynamics. Dr. Culick is a Fellow of the AIAA and of the International Academy of Astronautics. In 1981, he received the AIAA Pendray Aerospace Literature Award and in 1988 the JANNAF Combustion Subcommittee Recognition Award. From 1977 to 1986, Dr. Culick was a member of the AGARD Propulsion and Energetics Panel, resuming that position in 1994, until the destruction of AGARD. He has been a consultant to all of the major U.S. rocket companies as well as to various government organizations. As part of his interest in aeronautical history and early aviation, since 1978 Dr. Culick has been Project Engineer and designated First Pilot in a project sponsored by the Los Angeles Section of the AIAA. The project exists to build a full-scale wind tunnel model of the Wright 1903 Flyer (tests completed) and a flying version to be flown in 2003. Dr. Culick has published numerous papers on aviation history, the work of the Wright Brothers, and the AIAA project. He coauthored the recent book On Great White Wings-The Wright Brothers and the Race for Flight, an illustrated history of the race to invent the first powered aircraft. Currently, he is also collaborating with the Chair of Aerodynamics at the Moscow Aviation Institute and the Director of TsAGI, the Russian Center for Aerodynamics and Hydrodynamics, on reviews of Russian aerodynamics in the 20th century.

Presented as Paper 2001-3385 at the AIAA/ASME/SAE/ASEE 37th Joint Propulsion Conference, Salt Lake City, UT, 8-11 July 2001; received 3 August 2002; revision received 5 December 2002; accepted for publication 9 December 2002. Copyright (C) 2002 by F. E. C. Culick. Published by the American Institute of Aeronautics and Astronautics, Inc., with permission. Copies of this paper may be made for personal or internal use, on condition that the copier pay the $\$ 10.00$ per-copy fee to the Copyright Clearance Center, Inc., 222 Rosewood Drive, Danvers, MA 01923; include the code 0001-1452/03 \$10.00 in correspondence with the CCC. 
discoveries and developed the first successful airplane. Technically, their greatest fundamental achievement was their invention of threeaxis aerodynamic control. Less obviously, their success was a consequence of style, their manner of working out their ideas and of progressing systematically to their stunning achievements. They were indeed the first aeronautical engineers, understanding as best they could all aspects of their aircraft and flying. They were thinkers, designers, constructors, analysts, and especially flight-test pilots. Their powers of observation and interpretation of the behavior of their aircraft in flight were remarkable and essential to their development of the airplane. Their work in the period 1899-1905 constitutes the first true research and development program carried out in the style of the 20th century. As the centenary of their first powered flights approaches, the Wright Brothers' magnificent achievements excite growing admiration and respect for their achievements. The broad features of their accomplishments have long been well known. Only in the past two decades has serious attention been directed to the scientific and technical content of their work, to explain the nature of the problems they faced and how they solved them. After a century's progress in aeronautics, the principles, understanding, and methods not available to the Wrights provide the basis for interpretingin modern terms the experiences that the Wrights themselves documented so meticulously in their diaries, papers, and correspondence. It is a unique opportunity in the history of technology.

\section{Historical Background}

A considerable body of aeronautical knowledge existed at the end of the 19th century. The basic aerodynamics required to invent a successful aircraft had long been known: the lift and drag on a surface placed in a steady stream. Construction methods familiar from bridges, boats, and kites could be and were adapted for flying machines. Finally, recent progress in the development of internal combustion engines and lightweight steam engines practically solved the problem of having sufficient power.

Thus the problem of mechanical flight came down to one of geometry: Find an array of surfaces large enough to generate the lift required and so arranged that the pilot can control stable and maneuverable flight. That was essentially the problem that the Wrights solved to make possible their first powered flight (Fig. 1) and for which they received their 1906 patent, never broken. The Wrights knew and thoroughly understood the state of aeronautics when they began their work. They profited from the successes and failures of others. Someone else could certainly have been first to invent a successful airplane and would have in the absence of the Wrights. It is important to understand the historical context for the Wrights' work and to appreciate the fundamental importance of their style of research and development in making them succeed first.

In 1799, 26-year-old George Cayley (1773-1857) sketched what we now recognize as the familiar conventional configuration of an airplane: a cambered wing having dihedral, an aft vertical tail, and an aft horizontaltail $\left(\right.$ Gibbs-Smith $\left.{ }^{1}\right)$. Cayley's choice for the airfoil was based on aerodynamic characteristics of airfoils tested by him and his predecessors using various forms of a whirling arm apparatus

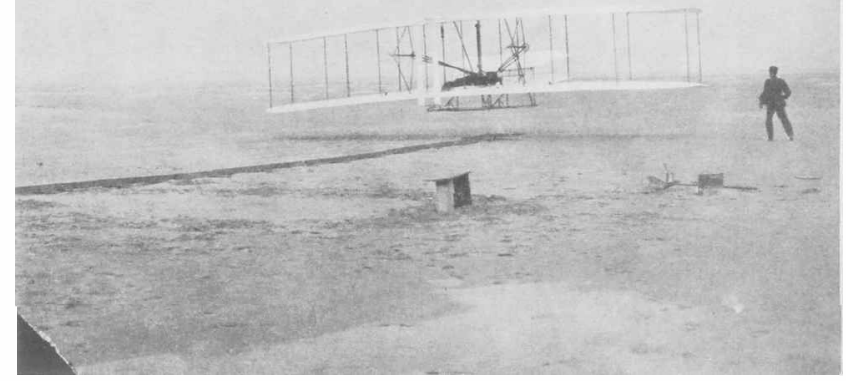

Fig. 1 First successful powered flight, 17 December 1903; Wilbur is at the right wing, and Orville is the pilot. invented by Benjamin Robins in 1742. Cayley himself invented dihedral as a means for maintaining equilibriumin roll. The vertical tail provided directional stability, like the feathers on an arrow, and in Cayley's view would also be used for steering, as a boat's rudder serves. By analogy, the horizontaltail gave stability in pitch. It turned out later that Cayley was half right on both counts.

Cayley did not formally apply Newton's laws for translationaland rotational motions to the airplane. He produced no mathematical descriptions for the motions of an aircraft and, therefore, had no quantitative basis for designing his flying machines. However, he had things right at the level he worked. With his first efforts he established the principle that he later explained thoroughly in a series of papers: The means of producing lift to compensate weight must be distinct from the means of generating thrust. ${ }^{2-4}$ It was a revolutionary idea at the time. He properly shifted attention to artificial flight from simple imitation of birds to development of fixed-wing aircraft.

Those ideas dominated all attempts to invent aircraft in the 19th century. Three immediate predecessors of the Wrights were particularly important to their work. Alphonse Pénaud (1850-1880) in France adopted Cayley's design and flew the first powered mechanical flying machine, a small rubber-powered model. He had the clever idea to use twisted rubber strips as the source of power for a propeller. In a short paper describing his model, Pénaud gave the first explanation for the action of an aft horizontal tail to provide stability in pitch. ${ }^{5}$ In France, the surface became known as the Pénaud tail.

The most important immediate predecessor of the Wrights was Otto Lilienthal (1848-1896). Educated and professionally successful as a mechanical engineer, Lilienthal made his mark following his boyhood ambition to build a successful flying machine. His two most influential contributions were his realization and demonstration that, to build a successfulairplane, it was necessary to learn how to fly and his extensive tests of airfoils, producing the first systematic data for lift and drag of a variety of airfoils. Less well known is that one of Lilienthal's results also contributed to Kutta's first paper on airfoil theory ${ }^{6}$ : He emphasized the property of a good airfoil that the flow should be smooth at the trailing edge. Carrying out his own instruction to fly, Lilienthal built a series of successful gliders having essentially Cayley's configuration. Lilienthal's results were influential particularly because they were widely reported and illustrated and because of his book Birdflight as the Basis of Aviation, ${ }^{7}$ published in 1889 .

Lilienthal inspired four followers: Percy Pilcher (1866-1899), a Scot, who, like Lilienthal, was killed when a gliding test ended in a crash; Octave Chanute (1832-1910), who built several gliders after Cayley's and Lilienthal's general design; Ferdinand Ferber (18621909), who began his gliding tests in 1899; and the Wrights. Ferber's most significant accomplishment was his successful motivation of a group of enthusiastic aviation pioneers in Paris. His contacts with the Wrights led, indirectly, to the agreement the Wrights eventually struck with a French syndicate to fly publicly first in France in 1908

Octave Chanute was the third predecessor of the Wrights to hold an important position in their developmentprogram, 1899-1905. He provided guidance to the existing literature and accomplishments by others with his important book Progress in Flying Machines. ${ }^{8}$ Technically, his use of the Pratt truss was adapted by the Wrights as their biplane configuration. Equally important was Chanute's role as a kind of sounding board during the Wright's intensive work from 1900 to 1905 . There is no evidence that he provided any technical contributions to their success other than the Pratt truss, but he and Wilbur exchanged many informative detailed letters, particularly on matters relating to the measurement and interpretation of lift and drag.

By the end of the 19th century, it seemed that much of the basic knowledge was in hand for the invention of powered piloted flight. As a consequence of the progress achieved primarily by Cayley, Pénaud, and Lilienthal, a successful configuration had been established. The recent invention of the lightweight internal combustion engine solved the problem of propulsion, although the known propeller designs had efficiencies well below what would soon become available. 
However, the gap between what was known and what was required for a practical airplane was larger than generally appreciated. Only the Wright Brothers recognized the extent to which the great problem of control still remained to be solved. Solving that problem led directly to the ability to execute circles and generally being able to maneuver the airplane. Lilienthal had demonstrated many successful straight glides by swinging his weight to maintain equilibrium in flight. Because his gliders were stable, he was able quite easily, by shifting his body laterally, to "direct our course of our flight to the right and to the left" (Lilienthal, "The Flying Man," in Chanute, ${ }^{8}$ p. 285). However, he was gliding, and not soaring for extended periods, and so he was unable to execute circles and did not investigate the intricacies of turning that the Wrights later discovered. Lilienthal did not require much controllability under his normal flying conditions. The first time he truly needed substantial control in pitch, his method of hang gliding failed him, causing his death.

Nearly all of the Wrights' predecessors and their contemporaries were preoccupied with constructing intrinsically stable aircraft, essentially large model airplanes. Moreover, none progressed far enough to become concerned with maneuverability, and hence, controllability was not an issue for them. The sole exception was Montgomery (1858-1911), who, in the 1890s, experimented with wing warping for control in roll (see Ref.9). His work was not publicized, and the Wrights independentlyinvented their method of wing warping. It is interesting and convincing evidence of their independence that Wilbur used a biplane design to incorporate warping, whereas Montgomery worked only with monoplane gliders. More to the point, before Montgomery could construct his planned powered aircraft he, too, was killed in a crash. Although his aircraft executed circles, he did not face the general problems of three-axis stability and control or the special difficulties of powered flight.

It is their explicit and persistent attention to those problems that really distinguishes the Wrights from their contemporaries and predecessors. They formulated and effectively solved, to the extent they required, problems of stability and control about all three axes. A wonderful feature of their style of working is their meticulous documentation of their observations and progress in the best tradition of flight testing. Parts of their diaries and letters read like daily reports of a modern research and development program. That is why we are able to puzzle out how they encountered and reacted to their discoveries of the motions of an unstable powered aircraft. Moreover, by examining closely the problems the Wrights encountered and the solutions they devised, we can clarify the deficiencies in their own understanding of the mechanics of flight and, hence, of their aircraft. Their stunning invention of the practical airplane placed the Wrights far in advance of their contemporaries. However, at the same time, the backward state of the general theory and understanding of flight mechanics hindered them and in fact caused them considerable difficulties. Indeed, the most serious gap in their knowledge was probably the basic reason for their unwitting mistake in selecting their canard configuration.

The chief intent of this paper is to interpret the technical achievements of the Wrights in the context of aerodynamics and flight mechanics developed in the decades during and after their program, which began in 1899 and had practically ended before Wilbur's death in 1912. Limited space has been devoted purely to description of their achievements and none to their private lives. Several books and popular publications thoroughly cover those historical aspects of the Wrights' careers, in particular Anderson, ${ }^{10}$ Combs, ${ }^{11}$ Crouch, ${ }^{12,13}$ Culick, ${ }^{14}$ Culick and Dunmore, ${ }^{15}$ Gibbs-Smith, ${ }^{16,17}$ Hooven, ${ }^{18}$ Howard, ${ }^{19}$ Jakab, ${ }^{20}$ Kelly, ${ }^{21}$ Walsh, ${ }^{22}$ and Wolko. ${ }^{23}$ All of these works, except Kelly's book, begin with the superb collection of the Wrights' diaries, papers, and correspondence prepared by McFarland. ${ }^{24}$

\section{The Greatest Deficiency in Early Aeronautics}

Hindsight is always a satisfying advantage for historical commentary. In the subject of flight mechanics, we now have essentially a complete and closed theory supported as well by decades of experimental and computational results. With all that experience, we can review the Wrights' work and appreciate even more deeply the problems they faced, the frustrations they must have felt, and the solutions they fashioned.

It is not an oversimplification to state that ultimately the general problem of achieving basic mechanical flight is equivalent to the problem of controlling rotations in three dimensions. Any investigation of rotations of an object leads very quickly to considerations of stability and, as a practical matter, control. Newton's laws show that, correspondingto the connection between translationalmotions and forces, rotational motions are the consequences of moments or torques acting on an object.

At the turn of the 19th century, inventors struggling to discover the "secret" to successful flight understood translational motions. They knew that steady rectilinear level flight requires that sufficient lift be generated to compensate the weight $(L=W)$ and that the thrust exactly equals the $\operatorname{drag}(T=D)$. They also had an intuitive notion, roughly at the level of understanding the principal of the lever, that an airplane will rotate unless the net moment acting is zero. Until the Wrights began their work, would-be inventors were concerned principally with equilibrium, that is, no rotation, of pitching or longitudinal motions; in particular, no rotation in pitch means zero pitching moment $(m=0)$.

None of the pioneers of flight, including the Wrights, wrote the equation arising from $m=0$ and, therefore, had no basis for exploring its implications. Their intuition stopped with the essentially correct conclusion that for equilibrium in pitch, the "center of pressure" must coincide with the center of gravity. Practical problems arise with interpreting and locating the center of pressure. The statement of coincidence is true if the center of pressure is that of the entire aircraft. Incorrect conclusions follow if only the center of pressure of the wing is understood. Failure to make and understand that distinction caused many difficulties for the aeronautical pioneers.

Because gravity acts in vertical planes, in the first instance it does not affect motions of an aircraft in roll and yaw (heading) away from steady level flight. Hence, equilibrium in roll and yaw seemed simpler than equilibrium in pitch. In fact, Cayley realized that stability of equilibrium was the primary matter for both roll and yaw. Stability of equilibrium means that if the aircraft is disturbed from an initial state of equilibrium, aerodynamicforces are naturally generated that tend to restore the equilibrium. Cayley concluded that an aft vertical tail and dihedral provided the restoring forces in yaw and roll, respectively. His conclusions are correct and apparently solved the problems of roll and yaw motions - until the Wrights recognized that piloted flight required control of roll and yaw, not merely equilibrium and stability.

Nevertheless, despite their brilliant successes, the Wrights never completely understood quantitatively the problem of stability of rotational motions. They shared that deficiency with all of their contemporary inventors, for the same reason: They never wrote or considered equations for rotational motions. Without the benefit of that formalism, they could not understand the true essence of stability of rotations. As a practical matter, they could not identify the physical contributions to stability, a failure that had significant consequences for their work.

1) Like their contemporaries, the Wrights could not properly solve the simplest problem of gliding; hence, they had only approximate means for designing their gliders.

2) Also like their contemporaries, they did not have the basis for investigating and understanding stability quantitatively.

3) They could not appreciate the importance of the zero-lift pitching moment and, therefore, did not realize the problem caused by selecting a highly cambered airfoil.

4) Therefore, they were not motivated to make extensive measurements of the aerodynamic pitching moment acting on an airfoil.

5) They had no way of estimating the location of the center of pressure of a complete aircraft. Hence, they could not entirely understand the significance of the location of the center of gravity.

The point, of course, is not to criticize the Wrights. On the contrary, our admiration for their marvelous accomplishments is increased when we understand more completely the contemporary state of aeronautics, the context in which they achieved their success. We can appreciate best that context and the Wrights' progress 
by interpreting as far as possible their aeronautical experiences in terms of what we understand a century later.

\section{The Wrights' Early Tests: A Kite (1899) and a Kite/Glider (1900)}

From observations of birds, Wilbur conceived the idea of controlling rolling motions of a flying machine by warping the wing. His practical realization was based on the Pratt truss, a bridge design, modified to the biplane configuration. At the same time, he invented the method of controlling motions in pitch by using a secondaryhorizontal surface, arranged so that its lift could be changed by rotation about a hinge line. He first incorporated both ideas in a 5-ft kite that he flew in August 1899. It was no ordinary kite, already having much of the geometry of the gliders the Brothers built in the following three years. Figure $2 \mathrm{a}$ is a photograph of a recent recreation. ${ }^{25,26}$ The afternoon's test program convinced Wilbur that his basic ideas were correct: He had the first flying machine controllable about two axes by actuating surfaces to exert appropriate aerodynamic forces and moments.

Wilbur and Orville were then faced with the problem of scaling from the kite to a glider sufficiently large to carry a $145-1 \mathrm{~b}$ pilot. As young boys, the Brothers had tried unsuccessfully to build a larger version of a tiny toy helicopter (Pénaud's design) their father had given them. Thus, building a successful large glider based on the kite design likely seemed less obvious to them than to us. The final craft, shown in Fig. $2 b,{ }^{24}$ had a wingspan of about $17 \frac{1}{2} \mathrm{ft}$, a wing area of $165 \mathrm{ft}^{2}$, and a control surface with an area of $12 \mathrm{ft}^{2}$.

In this first phase of their flight-test program, the Wrights were concerned primarily with two questions: Would the pilot be able to operate the pitch and roll controls effectively to maintain the machine in an equilibrium state of steady level gliding? Would the biplane configuration produce sufficient lift to sustain steady gliding with a pilot? The Brothers sought the answer to the second question by making measurements of lift and drag using a spring scale with the glider tethered as a kite. The lift-to-drag ratio was a low 6 , but more disappointinglythe lift was less than what they had calculated with Lilienthal's data. It was a large difference. Wilbur noted in his

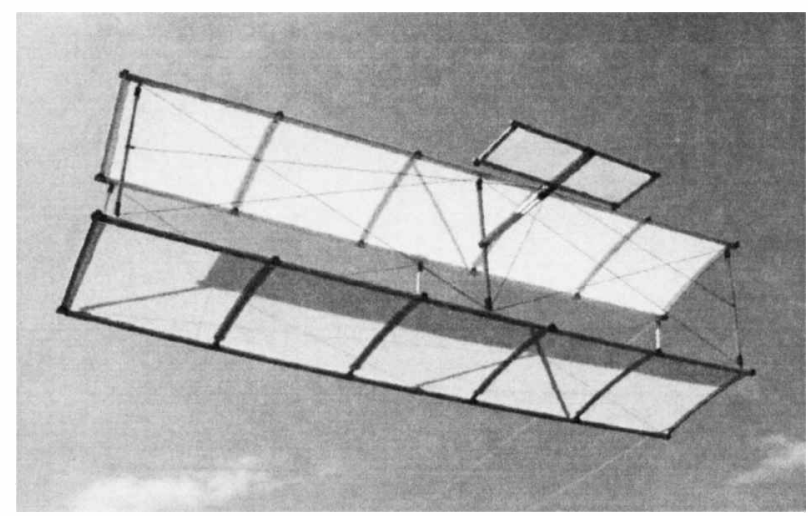

a) 1899 kite $^{26}$

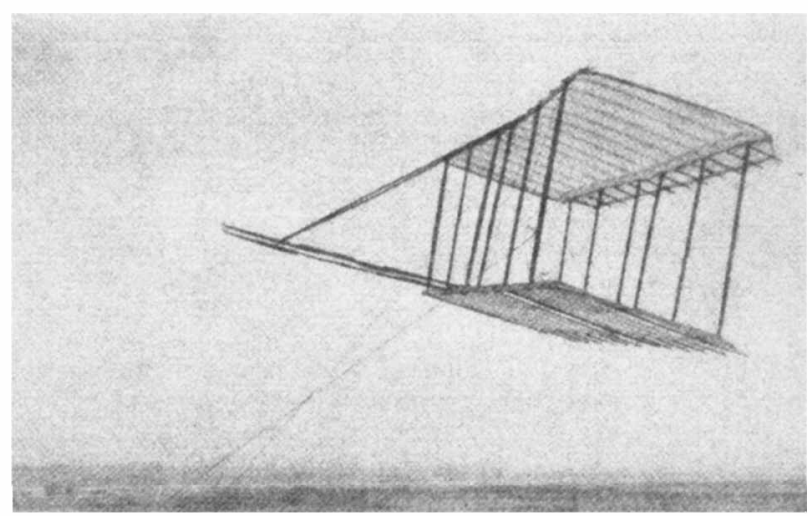

b) 1900 kite/glider ${ }^{24}$

Fig. 2 First demonstrations of two-axis control.
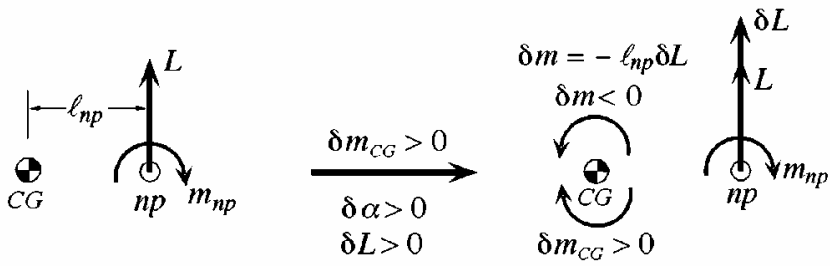

a)

b)

Fig. 3 Intrinsic stability when the c.g. lies forward of NP.
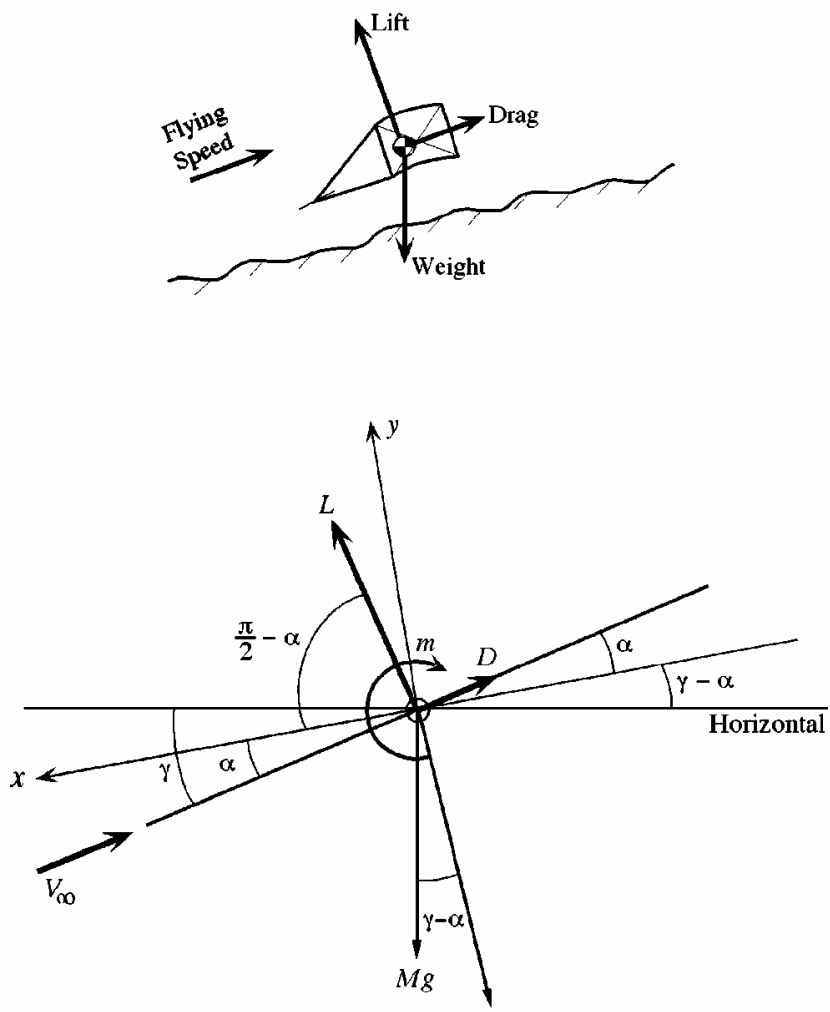

Fig. 4 Forces and moment for the elementary gliding problem.

1901 paper $^{27}$ that "We found that while it was supported with a man on it in a wind of about 25 miles, its angle was much nearer twenty degrees than three degrees." What they didn't know was that at 20-deg angle of attack, the glider was on the verge of stalling-if not already in the far side of stall see Fig. 3a. Because of uncertainties in estimating values in the full-scale tests, the angle Wilbur cites is not the same as that used in the graph: The true angle of attack in his case was probably less than $20 \mathrm{deg}$.

More positively, 2 min of gliding convinced Wilbur that his method of control worked well in flight, definitely superior to Lilienthal's technique of shifting the pilot's position. He was able to execute a few short glides, experience far short of the many minutes or hours he had hoped for, and he did not try to turn.

\section{The Elementary Problem of Gliding}

The Wrights apparently left no notes explaining the details of their calculations relating to the gliding problem. However, it is clear from their letters and entries in their diaries that they (most likely Wilbur) determined the sizes of their 1900 and 1901 gliders by making estimates, rather than carrying out a thorough analysis. They used Lilienthal's data and considerations of lift and drag only. Their ignorance of the equation for pitching moments necessarily caused their calculations to be approximate.

Consider the elementary problem of steady rectilinear gliding shown in Fig. 4. The machine is treated as a point mass $M$ moving in a vertical plane. Its motion is the result of actions by the forces of lift, drag, and gravity, as well as the pitching moment $m$. By convention, the lift $L$ and drag $D$ act, respectively, perpendicular and parallel to the direction of motion at velocity $V_{\infty}$. The velocity 
lies at the path angle $\gamma$ to the horizontal. Let $x$ and $y$ be orthogonal axes fixed to the glider as shown in Fig. 4, with origin at the center of gravity (c.g.). For steady gliding, the net force and moment must vanish. In the $x-y$ coordinate system, the three conditions are

$$
\sum^{i} F_{x_{i}}=0: L \cos \left(\frac{\pi}{2}-\alpha\right)-D \cos \alpha+M g \sin (\gamma-\alpha)=0
$$

$$
\sum^{i} F_{y_{i}}=0: L \sin \left(\frac{\pi}{2}-\alpha\right)-D \sin \alpha-M g \cos (\gamma-\alpha)=0
$$

$$
\sum^{i} m_{i}=0: m=0
$$

For small angles, these equations are

$$
\begin{gathered}
L \alpha-D+M g(\gamma-\alpha)=0 \\
L-D \alpha-M g=0 \\
m=0
\end{gathered}
$$

Let $S$ be the wing area, $c$ the wing chord, and $q_{\infty}=\frac{1}{2} \rho V_{\infty}^{2}$ the dynamic pressure and divide the three equations by $q_{\infty} c$ to find

$$
\begin{gathered}
C_{L} \alpha-C_{D}+w / q_{\infty}(\gamma-\alpha)=0 \\
C_{L}-C_{D} \alpha-w / q_{\infty}=0 \\
C_{m}=0
\end{gathered}
$$

where $w=M g / S$ is the wing loading. The lift, drag, and moment coefficients are

$$
C_{L}=L / q_{\infty} S, \quad C_{D}=D / q_{\infty} S, \quad C_{m}=m / q_{\infty} S c
$$

For the speed range of gliding, the coefficients $C_{L}, C_{D}$, and $C_{m}$ depend only on the angle of attack $\alpha$. Hence, for a specific glider, Eqs. (3a-3c) contain three unknown quantities: $\alpha, \gamma$, and $q_{\infty}$ or, for a given density (or altitude), glide speed $V_{\infty}$. If the moment equation, $C_{m}=0$, expressing what is usually called the trim condition, is ignored, one is left with two equations for the three unknownspath angle $\gamma$, angle of attack $\alpha$, and gliding speed $V_{\infty}$. A unique solution to that problem does not exist. For a proper result, $C_{m}$ must be expressed in terms of its contributions from the wing, tail, and other structural components; then $C_{m}=0$ becomes the third equation needed to solve the simple gliding problem uniquely.

Evidently the Wrights must have found themselves in a quandary because they appealed only to Eqs. (3a) and (3b) or equivalentforms. The only way out is to guess the value of one of the unknown quantities and solve the two equations for the remaining two unknowns. Although we do not know exactly what the Wrights did, we can infer with nearly complete confidence that they assumed the glide speed, leaving the path angle and the angle of attack to be calculated. In his marvelous paper "Some Aeronautical Experiments" prepared after his flying season of 1901 , Wilbur ${ }^{27}$ stated, referring to the matter of gaining extended gliding practice, "It seemed feasible to do this by building a machine which would be sustained at a speed of 18 miles per hour, and then finding a locality where winds of this velocity were common." He never clarified why he chose $18 \mathrm{mph}$, but it seems reasonable that he arrived at the number through a combination of estimates and review of average wind conditions in various locations. In any case, his reasoning led the Brothers to Kitty Hawk.

Chanute $^{28}$ in his article in Moedebeck's handbook ${ }^{29}$ also assumed the velocity to be known for his solution to the gliding problem. That article probably represents the accepted contemporary method for analyzing and "solving" the problem of gliding. Letters exchanged in January 1902 between Chanute and Wilbur confirm that they shared the difficulty of finding a way to solve the gliding problem.

Even with the velocity specified, solution to Eqs. (3a) and (3b) as part of the design process still requires iteration because the wing loading $w$ is not known initially. Hence, we speculate that for designing their gliders in 1900 and 1901, the Wrights might have used the following computational scheme:

1) The functions $C_{L}(\alpha)$ and $C_{D}(\alpha)$ are given by experimental results; in 1900 and 1901, the Wrights used Lilienthal's data.

2) Choose a value of the glide speed $V_{\infty}$. The Wrights seem to have sought a ground speed of about $4-6 \mathrm{mph}$. One of the reasons they chose Kitty Hawk as their testing ground was their expectation of steady wind speeds of $15-20 \mathrm{mph}$. Hence, $V_{\infty} \approx 20-25 \mathrm{mph}$.

3) Select a value of $w:=$ (gross weight)/(wing area). Equations (3a) and (3b) are then nonlinear algebraic equations in $\alpha$ and linear in $q_{\infty}$. With some difficulty, they can be solved numerically (trial and error if no computer is available) or graphically.

4) For the value of $\alpha$ found from solution to Eqs. (3a) and (3b), the lift coefficient and lift can be calculated and compared with the data used in step 1 . If the value is too close to the value for stall of the wing, then a new value must be set for $V_{\infty}$ or $w$ and the process (1-3) repeated.

Chanute's paper ${ }^{28}$ and correspondence suggest that the Wrights used the preceding scheme or a comparable method, to estimate a reasonable size for their gliders in 1900 and 1901. In subsequent years, their experience probably gave them the basis for estimates without extensive calculations.*

Part of the point here is to emphasize a difficulty unavoidable if (as the Wrights did) one fails to account for the moment equation. In the correct view of the gliding problem, satisfaction of the condition for zero total moment, Eq. (3c), is ensured by appropriate setting of the horizontal tail (or the canard). That is, the moment of the tail lift about the center of mass exactly compensates the moment generated by the lift of the wing imagined to be acting at the center of pressure. This analysis of the gliding problem, represented by Eqs. (3a-3c) can be confirmed quite well by tests with a simple hand-launched sheet balsa glider. Even if Eqs. (3a-3c) for equilibrium are solved correctly, the question of stability does not arise; it must be posed separately. To determine stability, a special analysis is required.

Consistent with ignoring the condition of zero net moment, the Wrights assumed that in equilibrium the canard carried no load and served only as a control device. Hence, their view of equilibrium in pitch required that the center of pressure of the wing alone must coincide with the center of gravity. In practice, it was quite possible that the canard carried a net load, but whether it actually did or did not would likely be obscured by the operational difficulties of piloting an airplane not only unstable in pitch, but possibly also untrimmed.

\section{The Center of Pressure, Aerodynamic Center, and Neutral Point}

From the earliest investigations of the force acting on an object in motion, before Newton's Principia, it was recognized that the pressure on the object's surface is continuous and nonuniform. The integral of the pressure over the surface is the net force. By analogy with the center of gravity, it is natural to introduce the idea of the center of pressure. If the object is imagined to be supported at the center of pressure, the aerodynamic forces generated by the motion cause no rotation: Its moment is zero when the net force is imagined to act at the center of pressure.

In the case of a freely flying wing, the weight is the only other force acting besides the net aerodynamic resistence. Thus the "support" is at the center of gravity, and if we neglect drag, there is no net moment on the wing when the center of pressure coincides with the center of gravity. If drag is accounted for, the statement still holds, but as shown in Fig. 4, the gravity force is decomposed into two components, one of which is compensated by the lifting part of the aerodynamicforce, and the other acts as a thrust force compensating the drag. It is a simple and correct idea, but extremely difficult to apply in practice to a complex aircraft. Much of the Wrights' confusion and problems with motions in pitch flow from their incomplete understanding of the matter.

*In a letter (1906) to the British Military Attaché in Washington,D.C., the Wrights allude to the possibility that they may have worked out a method for designing a powered aircraft for level flight, and possibly had prepared tables and charts for design (McFarland, ${ }^{24}$ p. 721). There is no evidence that their methods had progressed beyond that just described in the text, except that thrust generated by propellers replaced the action of gravity. 


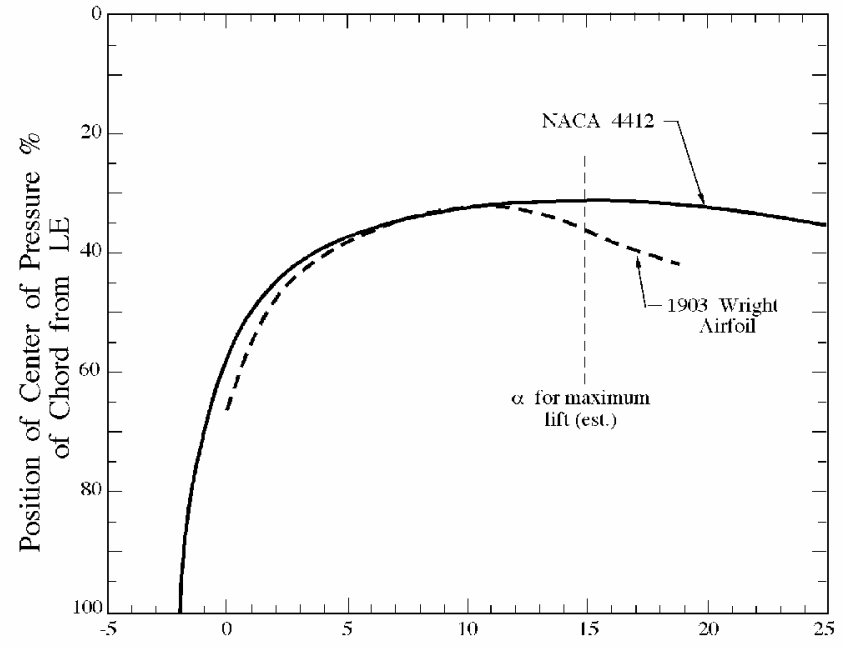

ANGLE OF ATTACK, $\alpha$ (degrees)

Fig. 5a Centers of pressure for the Wright 1903 airfoil $^{30}$ and the NACA 4412 airfoil. $^{30}$

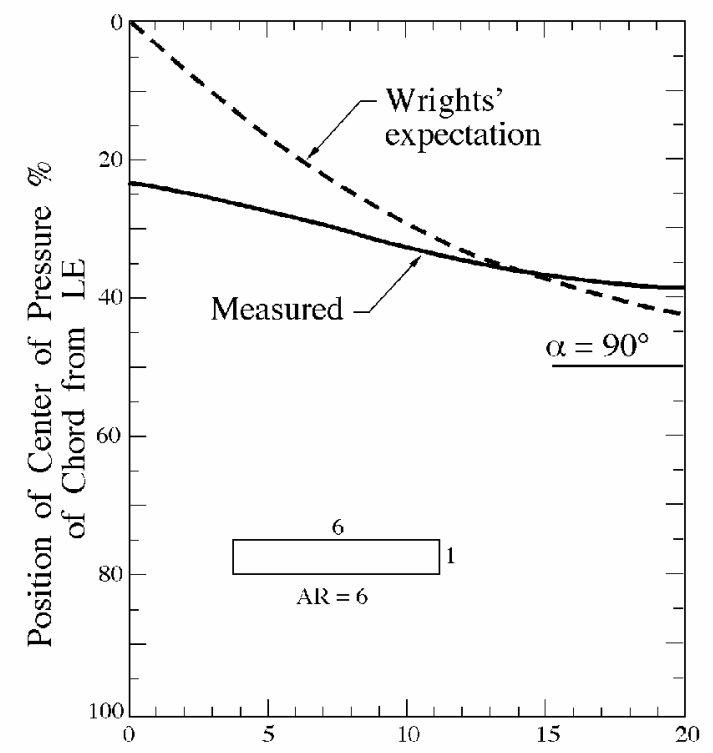

ANGLE OF ATTACK, $\alpha$ (degrees)

Fig. 5b Centers of pressure: ——, flat plate and - - - according to an early belief.

The practical difficulty with that interpretation of the condition for zero pitching moment is that the position of the center of pressure usually depends quite strongly on the orientation of the wing, that is, on the angle of attack. Moreover, the motion of the center of pressure with angle of attack causes a destabilizing pitching moment for the usual case of a cambered wing having fixed geometry. That is, the state of equilibrium existing when the centers of pressure and gravity coincide is unstable for angles of attack less than the values for stall. Figure 5 shows graphs of the center of pressure measured as functions of angle of attack for two airfoils, the Wright 1903 (see Ref. 30) airfoil and the NACA 4412 airfoil, ${ }^{31}$ popular for light aircraft, and a flat plate. ${ }^{32}$ For both airfoils, the center of pressure reaches its most forward location at an angle of attack in the vicinity of the value for maximum lift. Details of flow separation dominate much of the behavior, which is more complicated for the Wrights' highly cambered thin airfoil. Closer examination of the flow is required to explain why the measured center of pressure on a flat plate does not show reversal of its motion (Fig. 5b).$^{30}$ Viscous effects responsible for the flow separation cause the form of the flowfield in the immediate vicinity of the plate to vary strongly with angle of attack so that the plate effectively does not have a fixed shape. That result is largely due to the influence of a sharp leading edge.
Also in Fig. 5b, the dashed line shows the movement of the center of pressure that the Wrights believed to be the case, early in their work at least, until their gliding tests in 1901 showed otherwise. That supposed behavior is based on the following reasoning. When the airfoil (cf., the limit of a flat plate) is placed normal to the stream, the center of pressure is at or close to the midchord. As the angle of attack is reduced, the center of pressure evidently moves forward. The Wrights, following the beliefs of previous researchers summarized by Chanute, ${ }^{8}$ assumed that the center of pressure moves continuously forward as $\alpha$ is reduced from a large value, reaching the leading edge for $\alpha=0$. Equivalently, the center of pressure should move continuously aft from the leading edge as the angle of attack increases from zero. However, for an actual airfoil cambered concave down, the center of pressure moves forward from a position far downstream at zero lift, moves forward continuously as the angle of attack increases until stall occurs. Then the direction of motion reverses, and the center of pressure moves aft as the angle of attack is increased further.

Problems with controlling pitch, while gliding in 1901 and during some tests of the glider as a kite, led Wilbur to conclude that his previous notion of continuous forward motion of the center of pressure as the angle of attack is reduced was wrong. What he did not realize was that the most forward location of the center of pressure occurs when the airfoil is stalled in the vicinity of maximum lift. Hence, the correct view is that under normal flying conditions the center of pressure moves continuously forward as the angle of attack (and lift) increases up to the value for stall, where reversal of the motion occurs.

The particular way in which the center of pressure moves with change of angle of attack depends on the shape of the airfoil: There is no universal representation. Even if the Wrights, or anybody else, had investigated use of the moment equation for pitch, they would, therefore, have encountered unexpected complications when the idea of the center of pressure is used. In fact those complications are apparent in the literature of flight stability until the late 1930s when the distinguishedEnglish applied aerodynamicist. Gates introduced the idea of the neutral point (NP) for an aircraft. The neutral point is the aerodynamic center (a.c.) for a complete aircraft.

Von Mises ${ }^{33}$ and, later, independently, Tchaplygin ${ }^{34}$ discovered that every airfoil possesses an a.c. having location fixed as the angle of attack changes. It is a remarkable property valid for incompressible steady flow if the airfoil has fixed shape and if the Kutta condition (smooth flow at the trailing edge) is satisfied. The a.c. is defined as that point on an airfoil such that if the net lift is imagined to act there, the aerodynamic moment about the supporting axis passing through that point is independent of angle of attack. For airfoils normally used in practice, the a.c. is close to the quarter chord. Also, for the usual airfoil having camber line concave downward, the moment about the a.c. is negative in the conventional sense, acting to rotate the leading edge down.

As a practical matter, in writing the equation of pitching moment for an aircraft, assuming existence of the a.c. for a lifting surface means that, if drag is ignored, the surface is simply represented by the lift acting at its a.c. and a pitching moment (or better, a pitching moment coefficient $C_{m_{\mathrm{ac}}}$ ) independent of angle of attack. The difficulty associated with accounting for the motion of the center of pressure is eliminated. In fact, for a camber line concave downward, the forward movement of the center of pressure as the lift increases toward its maximum is a direct consequence of the existence of the a.c. Reversal of the forward motion occurs when the flow separates from the surface somewhere and ceases to have the ideal form required for existence of the a.c. The difference in the shapes of the two curves in Fig. 5a is due to differences in the way in which flow separation occurs. On the NACA 4412, the separation occurs first on the upper surface near the trailing edge and moves forward as the angle of attack increases. The flow is always attached on the underside. In contrast, due to the high camber and thin section of the Wright airfoil, flow separation occurs on the underside at low angles of attack.

The definition of the NP is the extension, to an array of surfaces, of the idea of the a.c. for a single surface. Thus the aerodynamic forces and moments acting on the various parts of an aircraft can be replaced by a single force acting at the NP and a moment about 
the NP that is independent of angle of attack. ${ }^{\dagger}$ It is an immediate consequence of its definition that as the angle of attack is increased the additional lift can be imagined to appear at the NP. The most important consequence of that behavior is that for static stability of an aircraft, the center of gravity must lie forward of the NP. That property is easily established with the help of Fig. 3 and the following argument.

Assume that the NP does exist (we have not proved it is true, but it is) having the property that the aerodynamic moment $m_{\mathrm{np}}$ about the $\mathrm{NP}$ is constantas the angle of attack changes. In Fig. 3a, the aircraftis assumed to be in equilibrium in level flight and so $L \ell_{\mathrm{np}}=m_{\mathrm{np}}$. Now suppose that the aircraft receives an external disturbance causing the nose to rise, a change of pitching moment about the center of mass, $\delta m_{\mathrm{cg}}>0$ according to the usual sign convention; the angle of attack is also increased, $\delta \alpha>0$. Hence, the lift is increased by $\delta L$. By assumption, $\delta L$ may be imagined to act at the NP, and $m_{\text {np }}$ is unchanged. If the center of mass is forward of the NP, the additional lift exerts a negative moment $\delta m=-\ell_{\mathrm{np}} \delta L<0$ about the center of mass, tending to oppose the external disturbance and restore the aircraft's initially level orientation. The configuration is, therefore, stable.

This is a perfectly general result, true for any aircraft, of which the Wrights were unaware - and could not be. In fact, no one knew this simple argument until more than 30 years later with the work of Gates, although the stabilizing effect of moving the center of gravity forward was already known with the work of Bryan and Williams ${ }^{35}$ and Bryan. ${ }^{36}$

In 1904, the Wrights decided to try to reduce the amplitude of pitching oscillations (undulations) they encountered by moving the center of gravity. Actually, they may have been dealing with a situation in which the oscillating motion was stable, but combined with a second motion exponentially unstable with a growth rate troublesomely rapid (described in Sec. IX). In any case, they first moved the center of gravity aft - exactly the wrong direction-by moving the engine. One flight was enough to reveal the error; a second confirmed it. For most of the remainder of their work with canard configurations, the Wrights carried ballast as far forward on the canard as they could, as much as $70 \mathrm{lb}$ on some occasions. That's roughly $8 \%$ of the gross weight of the aircraft.

\section{Relative Stability of Canard and Aft Tail Configurations}

Much has been written about the Wrights' problems of stability, or rather instability, of their canard aircraft. Occasionally, writers have incorrectly claimed that a canard configuration is necessarily unstable. By analogy with bicycles, that has been cited as the reason why the Wrights purposely avoided the known method (Cayley ${ }^{2-4}$ and Pénaud ${ }^{5}$ ) for obtaining stability by using an aft horizontal tail. With Wilbur's tests of his 1899 kite and their 1900 kite/glider, the Brothers knew that the machines would fly with the tail forward or aft of the main lifting surfaces. How much they had learned of the relative stability of the two configurations is not known. Orville noted in a letter home (McFarland, ${ }^{24}$ p. 38), "We tried it with tail in front, behind, and every other way. When we got through, Will was so mixed up he couldn't even theorize. It has been with considerable effort that I have succeeded in keeping him in the flying business at all." What is fairly clear is that Wilbur did not choose the canard configuration after considerations of stability, but rather for two reasons ${ }^{8}$ related to Lilienthal's death due to inadequate control of his conventional configuration: Wilbur thought he would have

\footnotetext{
${ }^{\dagger}$ The statement remains true if both lift and drag are accounted for.

${ }^{*}$ In this and the following two sections we are concerned only with static stability. No considerations are given to dynamics and rates of change are absent.

${ }^{\S}$ In his 1901 paper, ${ }^{27}$ Wilbur remarked “. . . we finally concluded that tails were a source of trouble rather than of assistance, and therefore we decided to dispense with them altogether." He refers here to both horizontal and vertical tails. During his final flights of 1901, Wilbur encountered unforeseen difficulties while trying to turn (Sec. VIII.B) Sometime after Wilbur's paper, Orville realized that they could overcome the difficulties by installing a vertical tail, which became part of their 1902 glider. Not until 1910 did the Wrights finally adopt the horizontal tail (Sec. XI).
}

better control with the canard, and it was both instructive and comforting to see the control surface during flight. According to Engler (private communication, 2002), Wilbur believed that he had more pitch control of his 1899 kite when the smaller surface was forward of the biplane cell. However, he was likely misled by the fact that the configuration with tail in front was unstable and, hence, very sensitive to his control inputs.

Because the theoretical basis was not yet established to understand the importance of forward location of the center of gravity, the Wrights simply had to learn from their testing how to deal with the serious pitch instabilities of their canard aircraft. Contrary to the view that has appeared in some accounts, there is no evidence that the Wrights intentionallydesigned their aircraft to be unstable - they just turned out that way. In fact, without paying attention to rotational motions in some detail — and that means understanding moments at a deeper level than the Wrights did — no one can have a firm grasp of what stability is really about. Bryan and Williams ${ }^{35}$ published the first paper correctly analyzing aircraft stability. They showed that for the center of gravity fixed relative to the larger surface, the configuration having a smaller surface aft is relatively more stable than that with a smaller surface forward, but both configurations could be made stable. The paper was unknown to those constructing aircraft at the time and of course appeared after the Wrights' commitment to the canard. Bryan ${ }^{36}$ later published his classical work forming the basis for all subsequent work on aircraft stability.

Elementary analysis of the wing/tail configuration may be found in standard texts of applied aerodynamics (e.g., Etkin ${ }^{37}$ and Perkins and $\mathrm{Hage}^{38}$ ). The main results needed for present purposes are given in Table 1. For simplicity we treat a single wing and secondary surface and assume that corrections for the biplane are absorbed in the formulas for the aerodynamic coefficients.

The coefficients of lift, $C_{L}$, and pitching moment, $C_{m_{\mathrm{ac}}}$, about the a.c.s are weighted values for the wing/tail configurations:

$$
\begin{gathered}
C_{L}=C_{L w}+\eta_{t}\left(S_{t} / S\right) C_{L t} \\
C_{m_{\mathrm{ac}}}=C_{m_{\mathrm{ac} w}}+\eta_{t}\left(c_{t} S_{t} / c S\right) C_{m_{\mathrm{ac} t}}
\end{gathered}
$$

An efficiency $\eta_{t}$ is defined equal to the actual dynamic pressure at the surface divided by $q_{\infty}$. Locations aft relative to the leading edge of the wing are denoted by the symbols $h$, distances divided by the wing chord. Thus, $h_{\mathrm{ac}}$ is the dimensionless distance of the a.c. of the wing from its leading edge, and $h$ is the dimensionless distance of the center of gravity from the leading edge, being positive for an aft location. If $h_{\mathrm{np}}-h>0$, the center of gravity of the aircraft is forward of the a.c. of the wing, representing a positive static margin.

Note that the lift curve slope of the tail $\mathrm{d} C_{L t} / \mathrm{d} \alpha$ is computed with respect to the angle of attack of the wing; it is better interpreted as

$$
\frac{\mathrm{d} C_{L t}}{\mathrm{~d} \alpha}=\frac{\mathrm{d} C_{L t}}{\mathrm{~d} \alpha_{t}} \frac{\mathrm{d} \alpha_{t}}{\mathrm{~d} \alpha}
$$

in which $\mathrm{d} C_{L t} / \mathrm{d} \alpha_{t}$ is the actual lift curve slope of the tail (approximately $2 \pi$, reduced by the effect of aspect ratio according to lifting line theory) and $\mathrm{d} \alpha_{t} / \mathrm{d} \alpha$ is due to the downwash for an aft tail and upwash for a canard, representing the aerodynamic interactions

Table 1 Some results for canard and conventional configurations

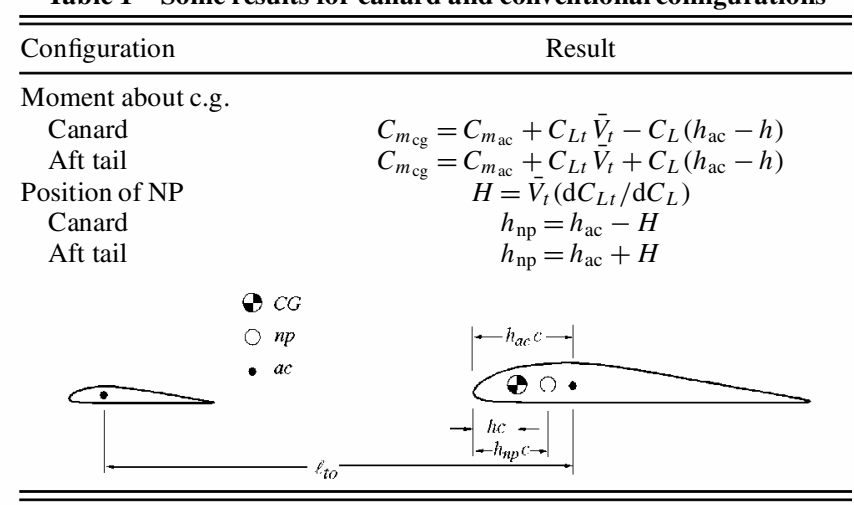


between the wing and the secondary surface:

$$
\frac{\mathrm{d} \alpha_{t}}{\mathrm{~d} \alpha}=\frac{\mathrm{d} \varepsilon_{t}}{\mathrm{~d} \alpha} \begin{cases}<0 & \text { aft tail } \\ >0 & \text { canard }\end{cases}
$$

If we assume that the wing and tail have lift curve slopes nearly the same, we can approximate $\mathrm{d} C_{L t} / \mathrm{d} C_{L}$ by

$$
\frac{\mathrm{d} C_{L t}}{\mathrm{~d} C_{L}}=\left(\frac{\mathrm{d} C_{L t}}{\mathrm{~d} \alpha_{t}}\right)\left(\frac{\mathrm{d} \alpha}{\mathrm{d} C_{L}}\right) \frac{\mathrm{d} \alpha_{t}}{\mathrm{~d} \alpha} \approx \frac{\mathrm{d} \varepsilon_{t}}{\mathrm{~d} \alpha}
$$

Then $H$ defined in Table 1 can be written

$$
H \approx \bar{V}_{t} \frac{\mathrm{d} \varepsilon_{t}}{\mathrm{~d} \alpha} \begin{cases}<0 & \text { aft tail } \\ >0 & \text { canard }\end{cases}
$$

where $\bar{V}_{t}=\eta_{t}\left(\ell_{t 0} S_{t} / c S\right)$ is the dimensionless tail volume, $\ell_{t 0}$ is the distance between the a.c.s of the wing and tail, and $\varepsilon_{t}$ is the conventional symbol for upwash or downwash. The formulas in Table 1 then give the results for the positions of the NP:

$$
h_{\mathrm{np}}=h_{\mathrm{ac}}-H= \begin{cases}h_{\mathrm{ac}}+|H| & \text { aft tail } \\ h_{\mathrm{ac}}-|H| & \text { canard }\end{cases}
$$

and $H$ may be approximated by Eq. (8).

Hence, the NP for a conventional configuration lies aft of the wing's a.c., but the NP of a canard lies forward. II That is the explicit realization, in modern terms, of Bryan and Williams's ${ }^{35}$ conclusion that the aft tail configuration is relatively more stable than the canard if the same surfaces are used. The more forward is the NP, the more difficult it is in practice to get a stable aircraft: The natural tendency during design and construction of an aircraft is for the c.g. to lie farther aft than desirable. Often then, either ballast must be added forward or the location of the wing is shifted, a common practice for model aircraft.

The Wrights' choice of the canard configuration was, therefore, already leading to a possible problem with pitch stability. That is an unavoidable consequence of the geometry and the aerodynamics. A canard can of course be designed to be intrinsically stable if the c.g. is far enough forward. In the case of the Wrights' canard, the problem is particularly difficult because of the mass distribution dictated by their design: The large weights (biplane cell, engine, and pilot) are all located such that their c.g. are close together and aft of the leading edge. Including the propellers and pilot, $94 \%$ of the gross weight of the 1903 airplane was contained in the biplane cell. That characteristic combined with the upper limit to the lift that the canard could produce (due to stall) meant that the 1903 Flyer could not be trimmed as a stable aircraft.

In the 1903 Flyer, the c.g. is about $30 \%$ of the chord aft of the leading edge and the NP is close to the leading edge. The aft vertical tail is already light and has little effect on the location of the c.g. There are only two ways to shift the c.g. significantly: add ballast to the canard and move the engine and pilot as far forward as possible on the wing. Estimates suggest that nearly $40 \%$ of the gross weight carried as additional ballast will move the c.g. to the leading edge of the 1903 Flyer if the positions of the pilot and engine are not changed.

When ballast is added, the flying speed of the aircraft increases and more power is required. Moreover, the canard must carry increased load to trim the airplane. By trial and error, the Wrights did as much as they could so far as moving the c.g. is concerned. They simply accepted their Flyers as unstable aircraft. Later models in 1908-1909 had the c.g. about $15 \%$ of the chord aft of the neutral point according to Hooven. ${ }^{18}$ Hence, their emphasis on control was absolutely necessary if their canards were to succeed.

\footnotetext{
IThe location of the NP for an array of surfaces can be (roughly) visualized as the weighted average of the locations of the NPs (a.c.) of the individual surfaces. It is a simple calculation for rectangular planforms, but otherwise the mean aerodynamic chord must be found for each surface; for example, see Perkins and Hage. ${ }^{38}$
}

Table 2 Canard lift coefficient for trim of the Flyers, Eq. (11)

\begin{tabular}{llll}
\hline \hline & \multicolumn{3}{c}{ Flyer } \\
\cline { 2 - 4 } Parameter & 1903 & 1905 & 1909 \\
\hline $\bar{V}_{t}$ & 0.134 & 0.355 & 0.320 \\
$-C_{m_{\mathrm{ac}}} / \bar{V}_{t}$ & 1.05 & 0.394 & 0.438 \\
$h_{\mathrm{ac}}-h$ & 0.050 & 0.120 & 0.050 \\
$-\bar{C}_{L} / \bar{V}_{t}\left(h_{\mathrm{ac}}-h\right)$ & 0.220 & 0.203 & 0.094 \\
$\bar{C}_{L t}$ & 1.27 & 0.597 & 0.532 \\
\hline \hline
\end{tabular}

\section{Importance of the Zero-Lift Pitching Moment $\boldsymbol{C}_{\boldsymbol{m} 0}$}

Consideration of the formulas for the pitching moment about the c.g. leads to a pleasing graphical interpretation of the rule that for stability the c.g. must lie forward of the neutral point. Simultaneously we will find that the pitching moment at zero lift has special importance not anticipated with the discussion in the preceding section.

From Table 1, the coefficient for the pitching moment about the c.g. of a canard is

$$
C_{m_{\mathrm{cg}}}=C_{m_{\mathrm{ac}}}+C_{L t} V_{t}-C_{L}\left(h_{\mathrm{ac}}-h\right)
$$

The lift coefficient $C_{L t}$ of the canard depends on the setting (deflection) of the surface and, due to upwash created by the wing, on the lift coefficient of the aircraft. In general, it cannot be taken equal to zero because for trim $C_{m_{\mathrm{cg}}}=0$ and Eq. (10) gives the condition (stable configuration)

$$
C_{L t} \bar{V}_{t}=C_{L}\left(h_{\mathrm{ac}}-h\right)-C_{m_{\mathrm{ac}}}>0
$$

With $C_{m_{\mathrm{ac}}}$ normally negative, $C_{L t} \bar{V}_{t}$ must be positive for stability, and the canard is a lifting surface.**

The slope of the moment curve is

$$
\begin{aligned}
\frac{\mathrm{d} C_{m_{\mathrm{cg}}}}{\mathrm{d} C_{L}} & =\frac{\mathrm{d} C_{L t}}{\mathrm{~d} C_{L}} \bar{V}_{t}-\left(h_{\mathrm{ac}}-h\right) \\
& =-\left(h_{\mathrm{ac}}-\bar{V}_{t} \frac{\mathrm{d} C_{L t}}{\mathrm{~d} C_{L}}\right)+h=-\left(h_{\mathrm{np}}-h\right)
\end{aligned}
$$

where $h_{\mathrm{np}}$ is given by Eq. (9) and $H$ is defined in Table 1 and approximated by Eq. (8). For stability, reasoning similar to that accompanying Fig. 3 shows that the slope must be negative for stability in pitch. Hence, the moment curve for a stable canard is like that shown in Fig. 6a. For linear aerodynamics the graph $C_{m_{\mathrm{cg}}}$ vs $C_{L}$ is straight only if the lift coefficient of the tail is constant.

Equation (10) gives the value for the moment coefficient at zero lift:

$$
\left(C_{m_{\mathrm{cg}}}\right)_{0}=C_{m 0}=C_{m_{\mathrm{ac}}}+C_{L_{t 0}} \bar{V}_{t}
$$

To have a stable moment curve with a trim condition, $C_{m 0}$ must be positive. In any case, for positive static stability $C_{m 0}$ cannot be negative because that would cause the graph to cross the axis at some point between the origin and the trim condition shown in Fig. 6 a. The second intersection would represent an unstable trim condition, not allowed under the circumstances enforced here.

Table 2 shows some estimated results for trim of the 1903, 1905, and 1909 Flyers, using the measured (Bettes and Culick ${ }^{39}$ ) value $C_{m_{\mathrm{ac}}}=-0.14$ for the 1903 Flyer and assuming $\bar{C}_{L}=0.6$. Those values are not accurate for the later aircraft but are close enough for the purpose here.

The results for $\bar{C}_{L t}$ show that the 1903 Flyer probably could not be trimmed because the canard would stall before reaching the lift coefficient 1.27 . Its moment curve is qualitatively like that in Fig. 6b, but the trim point cannot be reached. Because of their larger

\footnotetext{
** During the past 20-30 years, this result has often motivated enthusiastic support for canard configurations. The lifting surface relieves the wing, and, therefore, it is argued, reduces total induced drag. However, the argument is flawed, and the conclusion is incorrect because it does not account for interference between the lifting surfaces. The correct conclusion follows from Munk's stagger theorem: For fixed total lift, the induced drag depends, to good first approximation, only on the front view of the configuration and is independent of the fore-and-aft location of the surfaces.
} 


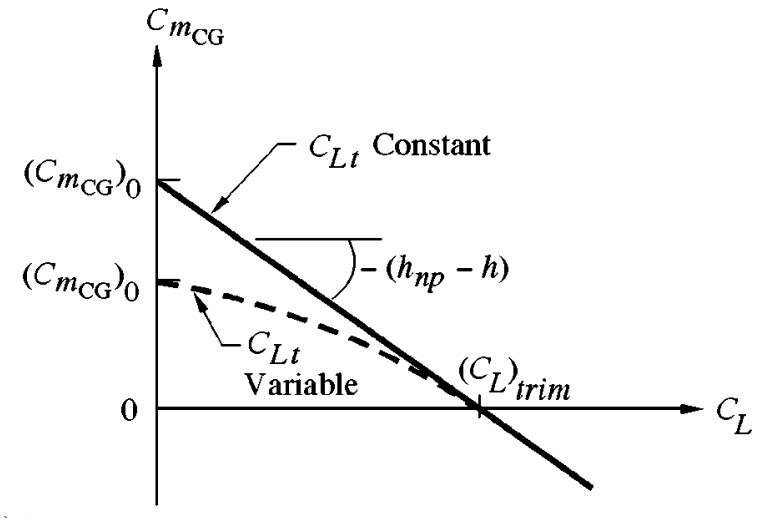

a) Statically stable

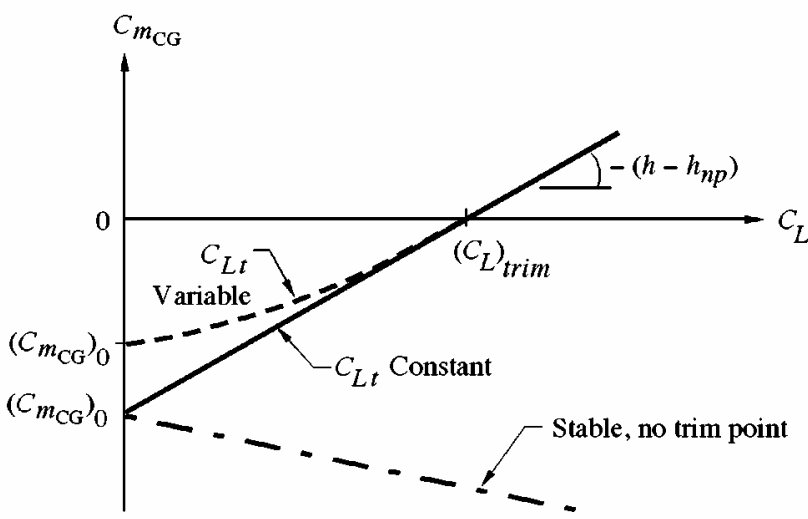

b) Statically unstable

Fig. 6 Moment curves for an aircraft.

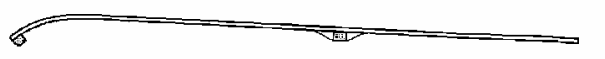

$1900(1 / 25)$
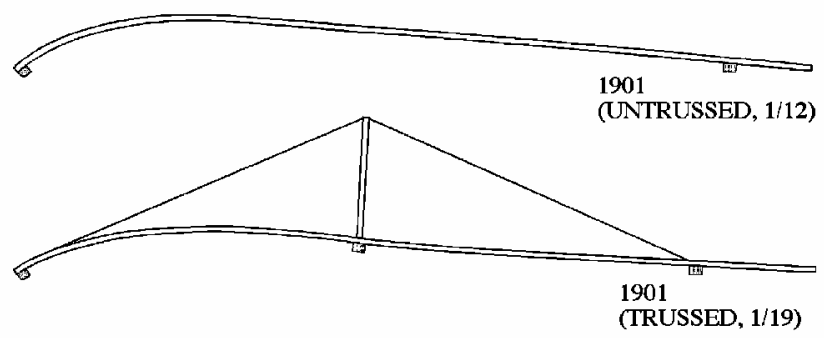

$1902(1 / 24-1 / 30)$

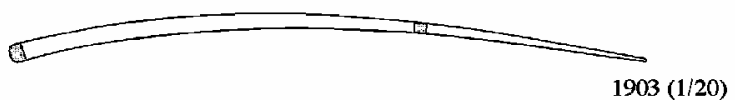

Fig. 7 Approximate profiles of the Wrights' airfoil 1900-1903: 1903 wing first to have fabric covering on both the top and bottom surfaces.

tail volumes, the 1905 and 1909 Flyers could be trimmed, although the equilibrium states would be unstable. Their pitching moments are similar to that shown in Fig. 5b for which there is an unstable trim point.

\section{1901: Year of Seminal Discoveries}

Based on their experience in 1900, the Wrights returned to Kitty Hawk in July 1901 with a glider designed primarily to solve the problem of developing more lift and, hence, allowing extensive gliding tests. It was larger, having wing span $22 \mathrm{ft}$ total, wing area $290 \mathrm{ft}^{2}$, and canard area $18 \mathrm{ft}^{2}$. Significantly, to conform more closely to Lilienthal's best profile, the Brothers used an airfoil shape having maximum camber in the range 1/12-1/18 along the span, in contrast to $1 / 25$ in 1900 . Figure 7 shows the airfoils. The total weight was about $240 \mathrm{lb}$ with pilot on board and the c.g. was initially $29 \mathrm{in}$. from the leading edge, about $37 \%$ of the chord.
Wilbur and Orville arrived at their camp on 10 July and departed on 20 August 1901. All of their flight testing was conducted during three weeks, ending on 16 August. It was a remarkably productive period. The Brothers made three discoveries fundamental to their success - all were results of careful tests and acute observations.

Apparently only Wilbur flew in 1901. During his first day's flying on Saturday, 27 July 1901 ("Made about 17 glides," McFarland, ${ }^{24}$ p. 71), he encountered his first serious problems of dynamics. At least two flights terminated in full stalls; he was unaware of the phenomenon and could not interpret correctly why the glider had "lost all headway." In response, he quickly moved forward to shift the c.g. —on both occasions the machine then settled horizontally to the sand, with no damage.

Wilbur thought that part of the problem was an oversized canard, causing control to be too sensitive. However, flight on the following Monday morning showed that reduction of the area to $10 \mathrm{ft}^{2}$ did not cure the problem. In the afternoon the Brothers flew the glider as a kite, with and without a person on board. Using spring scales attached to the restraining cords, they could infer values of the lift and drag. They made two important discoveries: As in their 1900 tests, the aerodynamic forces were much less than they had predicted with Lilienthal's tables, and the center of pressure did not move continuously forward as the angle of attack was reduced. The unexpectedly low values of lift and drag motivated the Wrights' famous wind-tunnel tests carried out in Dayton after they returned from their 1901 flying season.

The matter of the center of pressure was an immediate concern because it influenced directly the pilot's operation of the canard for pitch control and especially affected the response to unexpected disturbances of pitch attitude. To clarify the confusion, Fig. 8 is a replotting of the behavior shown by the dashed lines in Fig. 5 . Rather than accept the apparently strange motion of the center of pressure, Wilbur tried at first to modify the wing to produce the behavior he wanted, continuous motion of the center of pressure forward as the angle of attack is reduced. He correctly surmised that he could at least reduce the severity of the control problem by reducing the camber of the airfoil, even though this would also reduce the lift generated at a given angle of attack. First he tried reducing the camber by installing an additional spar between the leading edge and aft spar on the upper wing. Tests on Wednesday, 31 July, showed improved flying qualities.

Then the Brothers spent five days making further modifications, of which the most significant was introduction of additional spars on both wings and king posts with additional truss wires connecting the wings. That system, just visible in the photograph, Fig. $9,{ }^{24}$ allowed substantial adjustment of the airfoil, to give "... a shape which we hope will cause center of pressure to move forward like a plane at all angles" (McFarland, ${ }^{24}$ p. 81 ). See also Fig. 7 for a clearer view of the modification. Wilbur was determined to get the behavior he initially assumed. Figure 10 shows Wilbur's sketches of the airfoil on 27 July and after the modifications, on 7 August.

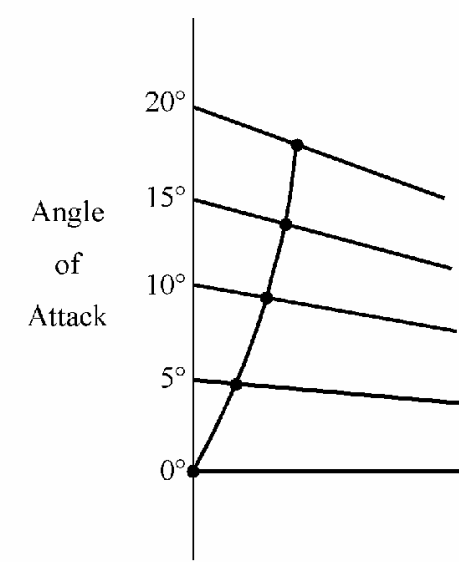

a)

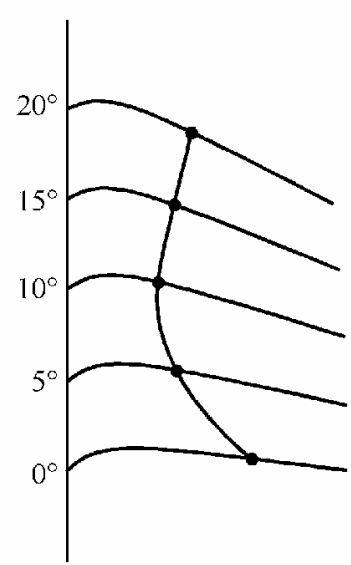

b)
Fig. 8 Motion of the center of pressure with angle of attack, data from Fig. 4: a) Wrights' incorrect expectation for a flat plate and, by assumption, for an airfoil and b) measured behavior of the Wright 1903 airfoil. 


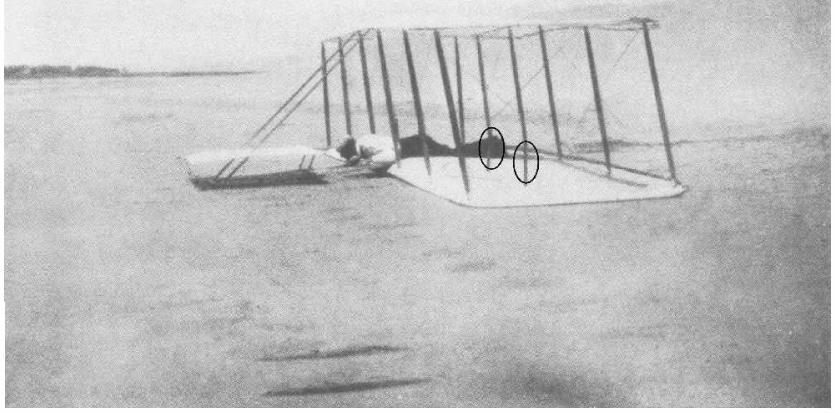

Fig. 9 Glider of 1901 after modifications to reduce the motion of the center of pressure: ellipses identify two king posts $\left(\mathrm{McFarland}^{24}\right)$.

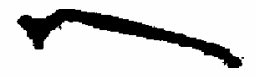

a)

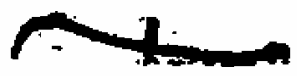

b)
Fig. 10 Wilbur's sketches of the airfoil shape on the 1901 glider $\left(\right.$ McFarland $\left.{ }^{24}\right)$ : a) initial highly cambered profile (27 July) and b) profile modified by trussing (7 August).

The improvement in performance and flying qualities was immediate. ${ }^{\dagger \dagger}$ From Wednesday, August 7, to Friday, August 16, Wilbur executed approximately 25 glides, of which the longest was $389 \mathrm{ft}$. However, one flight did end with the wings stalled.

\section{A. Interpretation of Wilbur's Difficulties with Motion} of the Center of Pressure

There is no doubt that Wilbur's initial incorrect expectation for the motion of the center of pressure contributed to the trouble he experienced during his first day of flying. Figure 11, based on the data plotted in Fig. 5, shows the graphs of center of pressure versus angle of attack for a flat plate and the 1903 Wright airfoil, which we use here for illustration. Any detailed differences from the behavior of the Wrights' first 1901 airfoil are not germane to the reasoning.

According to entries in his diary and remarks in his 1901 paper, ${ }^{27}$ Wilbur's idealized approach to understanding gliding proceeded roughly in the following way:

1) With the approximate scheme for solving the gliding problem (Sec. IV), estimate the angle of attack at which the lift is sufficient to compensate the total weight in steady gliding at the assumed flying speed. For simplicity here, assume that the canard carries no lift. ${ }^{*}$

2) For that angle of attack, locate the position of the center of pressure of the wing assuming the graph for a plane (Figs. 5 and 11).

3) When disturbances, that is, gusts of wind, occur, the angle of attack changes and the center of pressure moves according to the graph for the plane in Fig. 5. The lift then generates a moment about the center of mass and the canard must be actuated so its lift creates a compensating moment to maintain equlibrium.

It is the last step that contains the explanationfor Wilbur's difficulties because the sense in which the canard is actuated is determined by the direction of motion of the center of pressure. Before his gliding tests, Wilbur had assumed the behavior of a flat plate and based his planned control strategy on that assumption. A simple example shows how that strategy caused him to stall the glider.

Suppose that the state of (more-or-less) steady flight is such that the angle of attack and location of the center of pressure correspond

\footnotetext{
${ }^{\dagger}$ Almost certainly the apparent reflex in the airfoil shown in Fig. 10b had much to do with the improvement. It was a point missed by the Wrights, and from 1902 to the end of their work they used highly cambered thin airfoils without reflex. The significant and favorable consequences of reflex were later shown first experimentally by Turnbull. ${ }^{40}$ It is possible to design a reflexed airfoil having fixed location of its center of pressure, but at the expense of poor lift-to-drag ratio.

\$A lifting canard is easily accommodated within this scheme.
}

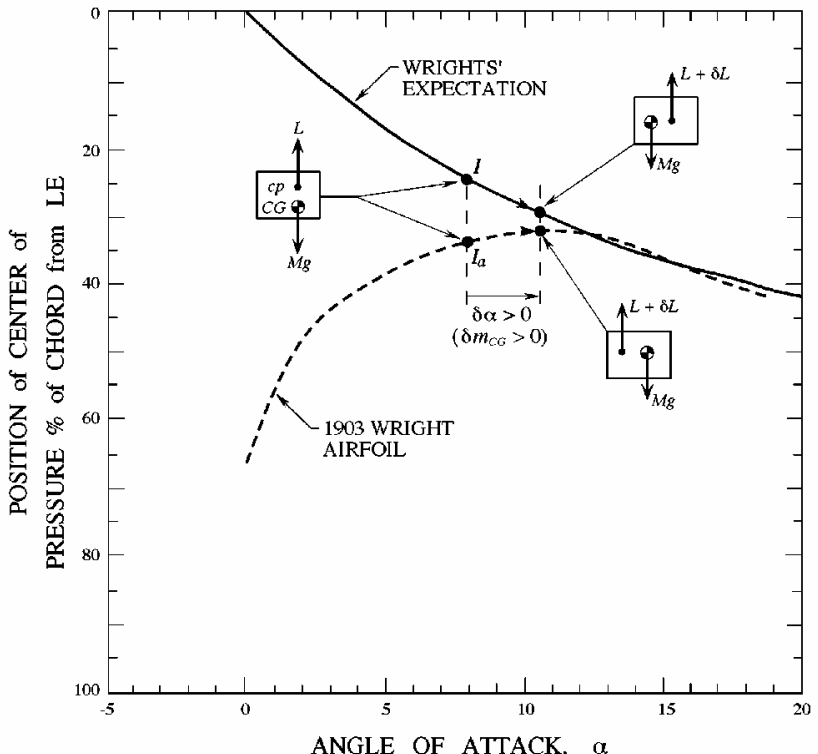

Fig. 11 Motion of the center of pressure as the angle of attack is changed: aerodynamic origin of the two stalls on 27 July 1901.

to the points $I$ and $I_{a}$ in Fig. 11. The point $I_{a}$ identifies the actual location of the center of pressure on the true graph $x_{\mathrm{cp}}(\alpha) ; I$ is on the graph of $x_{\mathrm{cp}}(\alpha)$ that Wilbur anticipated. Now suppose that a disturbance, that is, a wind gust, causes the angle of attack to increase by $\delta \alpha$. Hence, the center of pressure in the actual case moves forward, but Wilbur thought that it moved aft, as shown in the inserts. Hence, while in reality the pilot must exert a nose-down moment to restore the initial state, Wilbur rotated the nose of the canard upward, intending to exert a nose-up moment, compensating the nose-down (he thought) rotation caused by an aft displacement of the center of pressure.

In short, because he expected that the center of pressure would always move aft if the angle of attack increased, Wilbur's planned strategy for control in pitch was that, to maintain equilibrium, the pilot must cause a nose-up moment if the angle of attack increases, that is, if the nose appears to rise. If the initial operating point $I$ is at an angle of attack close to stall (but $\alpha<\alpha_{\text {stall }}$ ), then that control strategy could cause the glider to stall—and that is apparently what happened twice on the first day of tests in 1901.

What Wilbur and Orville called the "reversal of motion" of the center of pressure was their discovery of the correct motion of the center of pressure below the angle of attack for stall. It was clearly a crucial discoveryallowing them to continue their test flying successfully. Although eventually the Brothers had sufficient information to prepare graphs such as those in Fig. 11 (see Fig. $12^{24}$ here), they did not document the reasoning just described. Indeed, it is not an exaggeration to note that the Wrights truly understated this discovery of behavior fundamental to airfoils in general and especially crucial to continuation of their successful gliding tests.

\section{B. Wilbur's Discovery of Adverse Yaw}

Cayley and others before the Wrights, Lilienthal and Montgomery being the exceptions, assumed that turning in flight could be achieved by use of the vertical tail or rudder, in exactly the same way a boat is turned. Probably from his observations of birds in flight, Wilbur knew better. His correct idea was that, to generate the centripetal force required to set the airplane on a circular path, the airplane should be rolled to tilt the lift force (perpendicular to the wing surface) so that part of the lift would act toward the center of the intended circle. What he did not recognize until later was that, to cause the nose to turn in the direction of the desired turning motion, there must be a vertical tail to cause rotation in yaw. Without it, the airplane would begin to execute a circular path, but the nose would continue to point nearly in its initial direction.

However, the situation is worse, as Wilbur discovered in his first attempts. To roll the airplane, the lift on one wing is increased and 


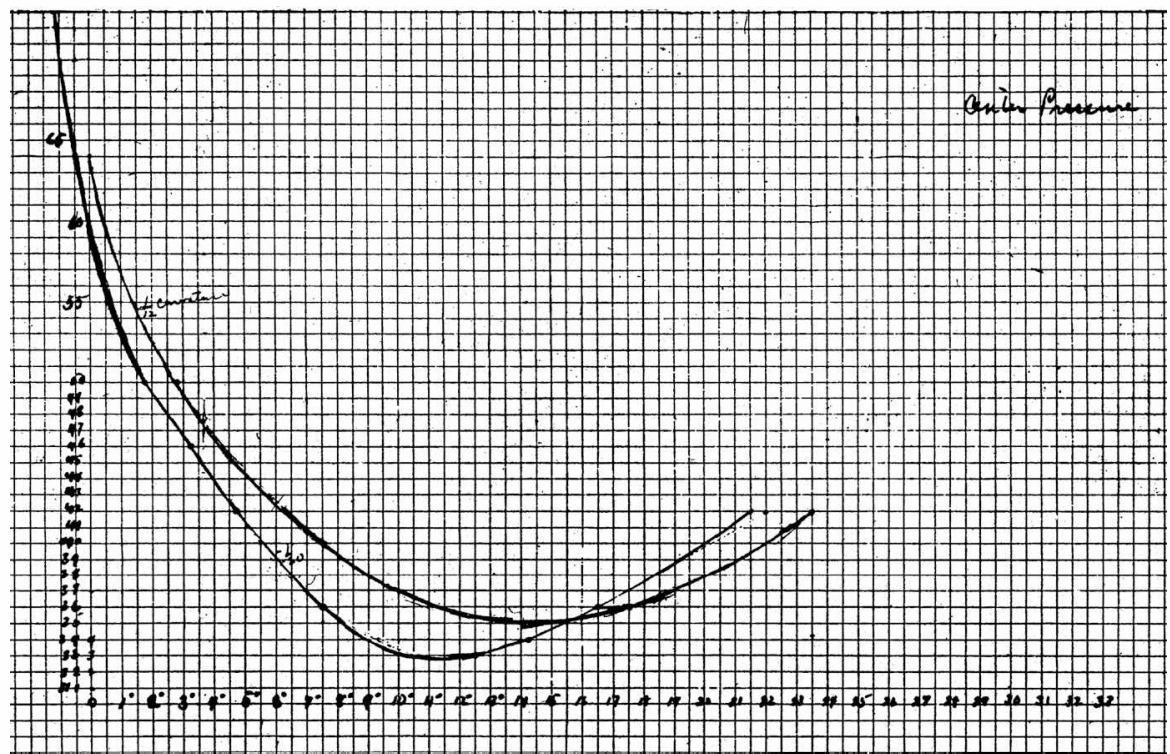

Fig. 12 Wrights' data for the center of pressure on two of their airfoils (McFarland, ${ }^{24}$ p. 503).

decreased on the other, in Wilbur's case by warping the structure. That control generates a roll moment. However, the drag on a wing has a part proportional to the lift. Hence, one wing has greater drag than the other. The differential drag causes the aircraft to yaw, and the nose actually swings in the sense opposite to that desired in the turn. That is what Wilbur discovered, a very keen observation indeed. Attempting to correct the unwanted motion tends to complicate things further, and the maneuver falls apart.

He entered his observation with the brief remark in his diary on Thursday, 15 August: "Upturned Wing seems to fall behind but at first rises." Then, in a letter to Chanute a week later, he reported, "The last week was without very great results though we proved that our machine does not turn (i.e. circle) toward the lowest wing under all circumstances, a very unlooked for result and one which completely upsets our theories as to the causes which produce the turning to right or left."

Thus, when the symmetry of the aircraft is broken, by warping the wing, lateral motions are induced. After 1901, as they developed their method of turning, the Wrights were forced to address problems of lateral motions as well as those of longitudinal motions.

Wilbur made a few glides on the day following his experience with adverse yaw. The Brothers then closed camp and returned to Dayton. In three weeks, test flying from 27 July to 16 August, they had made three basic discoveries whose deep significance they could not fully appreciate at the time. Their confirmation of measured values of lift and drag well below those reported by Lilienthal caused them to build their wind tunnel ${ }^{\S \S}$ and to carry out extensive tests of airfoils, wing planforms, and struts. When they ended the tests, they had the first systematic compilation of aerodynamic data suitable for designing aircraft. Those results served them through their entire program until Wilbur's death in 1912 brought their design and development program to its end. Less well known is their conclusion that Lilienthal's data were actually very good and that their low values for the aerodynamic forces were due to their use of the incorrect value of Smeaton's coefficient ${ }^{\text {TIII }}$ generally accepted at that time (Culick and $\mathrm{Jex}^{41}$ ). Their data gave them the correct value.

In contrast to their quantitative understanding of lift and drag, the Wrights seem to have been quite satisfied with qualitative results for motion of the center of pressure on a cambered airfoil-their second great discovery in 1901. Having established the correct way in

\footnotetext{
$\S \S$ The wind tunnel had been invented by Frank H. Wenham in 1871. In the 1890s, Albert Wells at Massachusetts Institute of Technology used the idea to measure the correct value of the drag on a flat plate oriented perpendicular to the flow in an air conditioning duct.

III Proportional to the drag of a square flat plate oriented perpendicular to the wind.
}

which the center of pressure moves as the angle of attack is changed, they were satisfied because it was the basis for a correct strategy of pitch control. Their incomplete understanding of moments did not allow them to investigate the quantitative nature of equilibrium, stability, and control of pitching motions. It was enough for them to know that when their aircraft began to "lose heading" as it entered a stalled condition, they should use the canard to generate a nose-down moment and gain airspeed. That understanding became a key part of the final step in development of their practical aircraft in 1905.

Wilbur's identification of adverse yaw, possible only because he was a test pilot flying his own creation, was the third of the Wrights' great discoveries in 1901. The solution to the problem of executing correct turns rested on having a control moment about the yaw axis. Sometime later, during their design of the 1902 glider, Orville realized that their aircraft needed a vertical tail to give them the necessary yaw moment.

\section{The Wrights Discover Longitudinal Dynamics}

The Wright Flyers had limited flexibility to exercise control, for example, with wing warping. However, because of the arrangement of truss wires, the Flyers can be approximated as rigid structures when the controls are fixed. That assumption has a wonderful consequence: A century's progress in the science of the flight mechanics of rigid aircraft is immediately applicable to understanding the behavior of the Wright Flyer.

A rigid aircraft has six degrees of freedom. For small departures from a state of steady flight, the time-varying motions of a symmetrical aircraft can be separated into two uncoupled forms: longitudinal motions in the plane of symmetry and lateral motions out of that plane. The variables for the longitudinal motions are two translational velocities $u$ and $w$ in the forward and vertical directions and one rotational velocity $q$ for pitching motions.

\section{A. Normal Modes for Longitudinal Motions}

Stability of the translational motions is guaranteed by the presence of aerodynamic damping due to drag. If the aircraft is also statically stable in pitch - the c.g. lies ahead of the NP-then the aircraft possesses two oscillating modes of motion: the "phugoid" or long-period (low-frequency) mode and the short-period mode. If a conventional aircraft is rendered unstable by improper distribution of the payload, the common case is that the short-period mode degenerates to two exponential motions, one of which is unstable, while the phugoid remains. That is the case for the 1903 Wright Flyer.

To a good first approximation, the phugoid oscillation is a slowly decaying oscillation having period equal to $2 \pi \sqrt{ }(\bar{u} / g)$, where $\bar{u}$ is 
the average forward translational velocity. It is a relatively slow undulating motion involving periodic exchange of kinetic and potential (gravitational)energy. The angle of attack remains nearly constant. During a phugoid oscillation, the aircraft normally undergoes noticeable oscillations of altitude and speed.

In contrast, a stable short-period motion usually takes place with only small changes of altitude and speed and is independent of the phugoid motion. During a short-period motion, the nose bobs up and down, and the change of pitch angle relative to the horizon approximately equals the change of angle of attack. The aircraft is behaving much like a weathervane in pitch, the mass being the moment of inertia and the spring or restoring force is provided by static stability, that is, a negative slope of the pitching moment curve.

Probably the most common event causing the phugoid oscillation to appear is a change of altitude. The slow oscillation may be excited and cause some difficulty in trimming to the new altitude, particularly if the new altitude is higher than the initial altitude. Unless abrupt changes of the elevator are made, a stable short-period oscillation is not likely to be apparent. On the other hand, flight through choppy air will easily excite the short-period oscillation.

However, the pilot will always notice an unstable short-period oscillation, which occurs when the aircraft is statically unstable in pitch. The growth of the unstable exponential part requires active control. If also the phugoid happens to be excited, then the aircraft will execute oscillations superposed on the growing exponential; the result could be interpreted as an unstable oscillation. That became a characteristic of all of the Wright Flyers.

\section{B. Wrights' Experience with Longitudinal Dynamics: 1900-1903}

During their flying seasons of 1900-1903, the Wrights first encountered some symptoms of longitudinal dynamics of their unstable gliders and powered aircraft, but not until 1904 did they mention the presence of oscillations or "undulations." In 1900, the kite/glider was flown mostly as a kite, and so the general behavior just described in Sec. IX.A is not relevant. Their total free-flying time was of the order of $10 \mathrm{~s}$ or so, and the Wrights recorded only general observations. There is inadequate information to determine whether or not they had any direct experience with the longitudinal modes of motion. It does seem that the glider was probably unstable, requiring the pilot's constant attention even for such short flying times. The Wrights' two main conclusions from their tests in 1900 - that their design of pitch and roll controls worked well and that the lift and drag they measured were less than the values they had predicted with Lilienthal's data and formulas-were not related to dynamic behavior.

It was of course a differentstory in 1901. Wilbur's difficulties with pitch control necessarily brought problems of dynamics, mainly stall and recovery. His idea to reduce the camber of the airfoil to smooth the motion of the center of pressure seems to have done much more. The modification (Fig. 10) not only reduced the camber but also caused the profile to have roughly a reflexed shape, the trailing edge curling up. Both of those changes reduced the size of the negative zero-lift pitching moment, that is, the moment about the a.c.

A tailess aircraft can be made trimmable and stable in pitch if the airfoil is sufficiently reflexed that the zero-lift pitching moment is positive and the slope of the moment curve is negative (Fig. 6a). The Wrights of course had no idea about those characteristics, but Wilbur did find the modified version of the glider very flyable. In 1978, R. Young built a replica (Fig. 13a, photograph by T. Wright, 1978) of the 1901 glider flown in the television film "Winds of Kitty Hawk." Engler ${ }^{26}$ and his colleagues built and flew a replica of the 1901 glider at Kitty Hawk in October 2001, the centenary of Wilbur's significant flights. Both report that their versions (Figs. 13), ${ }^{26}$ which also contained the king posts and added truss wires to reduce the camber, flew very successfully even in winds lighter than those the Wrights had.

Kochersberger et al. ${ }^{42}$ have reported results of wind-tunnel tests of a full-scale replica of the 1901 glider, carried out in the $30 \times 60 \mathrm{ft}$ open section tunnel at NASA Langley Research Center. Their data show that the aircraft could be stably trimmed over a range of useful speed and lift coefficient. That result is direct explanation of the relative ease with which the Wrights and more recent builders of

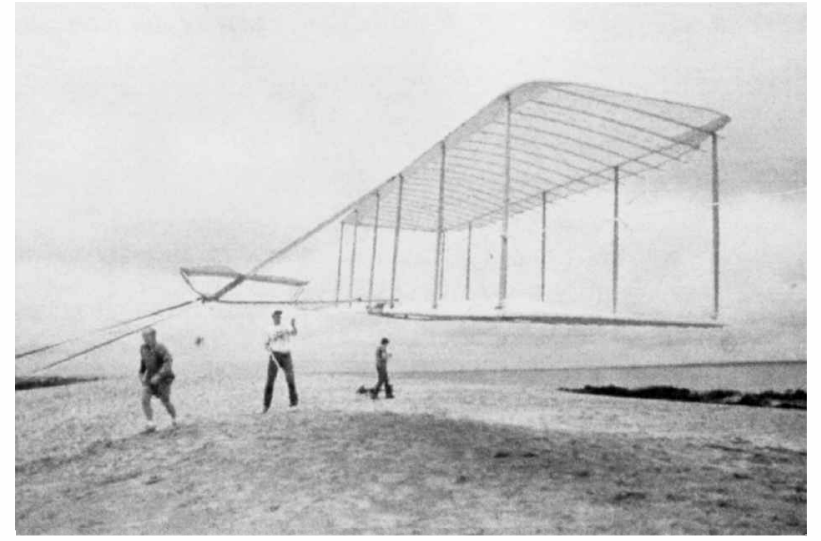

a) Young (by T. Wright, 1978)

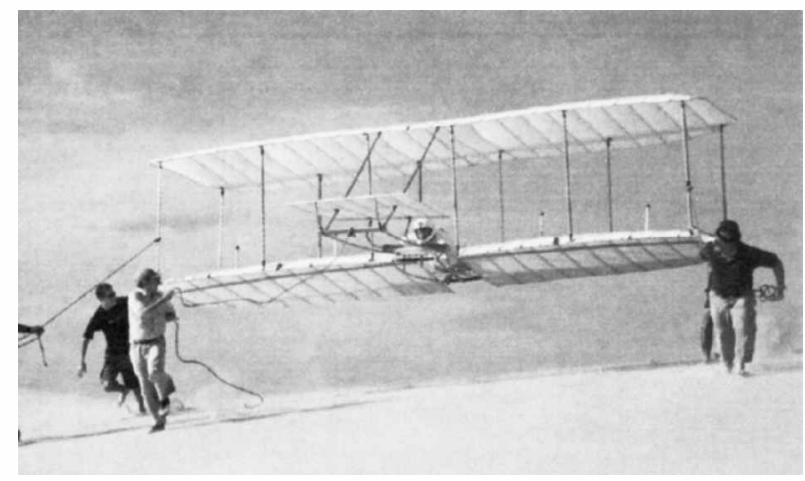

b) Engler (2001) ${ }^{26}$

Fig. 13 Photographs of recent recreations of the 1901 Wright glider.

the 1901 glider have found the machine to have reasonably good flying qualities.

Those results suggest that with their modification of their airfoil (Fig. 10) the Wrights had moved their design in the right direction, namely, they made the zero-lift pitching moment, or $C_{m_{\mathrm{ac}}}$, less negative. However, because they did not have the theoretical framework to understand the implications of what they had done, they were unprepared to take advantage of the improvement. They knew that they had successfully altered the motion of the center of pressure and had improved the controllability of the glider. However, they could not understand that more significantly in that process they had modified the pitching moment curve substantially, likely making the glider nearly stable in pitch. That was probably the one lesson presented to the Wrights that they did not learn well enough to apply to their powered aircraft.

Figure 7 makes the point, showing the airfoil sections for the 1900-1902 gliders and the 1903 Flyer, little changed in the 1904-1909 Flyers. Only approximations can be sketched for the 1900-1902 airfoils for which no accurate drawings exist. In particular, the 1902 glider had an airfoil possessing relatively low maximum camber, $1 / 24-1 / 30$, when constructed. Because of structural flexibility, the camber varied along the spans of the gliders, so that no unique values can be assigned.

All evidence suggests that the 1902 glider did not present serious problems of longitudinal stability and control. The lightweight structure and the relatively forward position of the pilot favored a position of the c.g. that, with the airfoil used, probably gave a machine that was only mildly unstable in pitch, possibly even stable. Several replicas have been made and successfully flown repeatedly during the past 25 years or so: Young (private communication explaining earlier gliding experience, 2002), Engler (private communication, 2002), Valentine (private communication, 2000), and Kochersberger (private communication, 2002). Young has reported in private conversation that, so far as the pitch instability is concerned, flying the 1902 glider was "not much different from riding a bicycle."

On the contrary, when the Wrights scaled up their 1902 design and added a propulsion system, the behavior in flight was quite different. 
Root Locus for Pitching motion

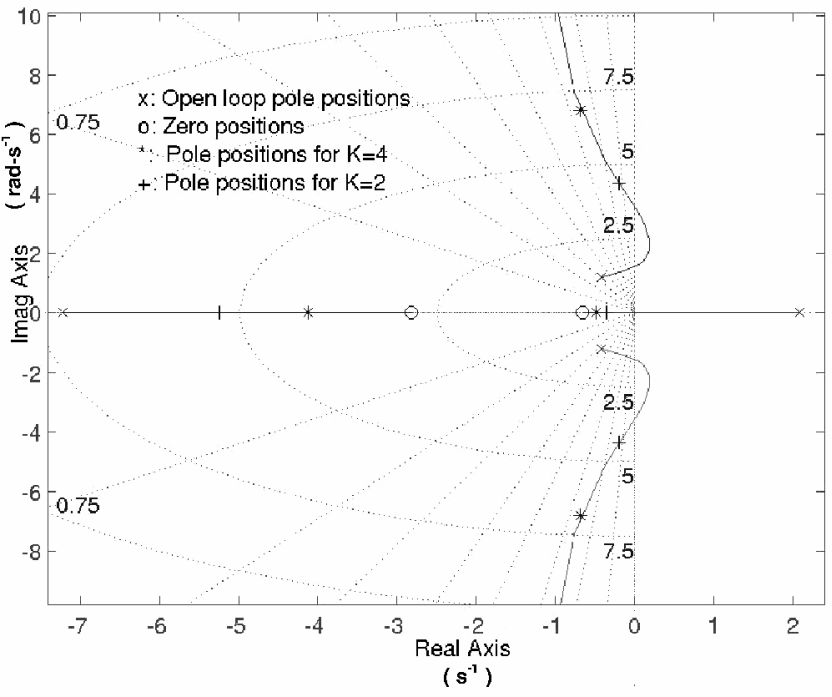

Fig. 14 Locus of dynamic roots for longitudinal motion of the 1903 Wright Flyer; pilot control law: canard deflection proportional to pitch angle error, gain coefficient $K$.

A major reason for the problems of pitch motions with their powered aircraft was their choice of airfoil based on best lift-to-drag ratio with no attention to pitching moment. That is a serious fundamental differencebetween the aerodynamicsof the 1902 glider and the 1903 Flyer. The 1903 airfoil had maximum camber greater than that of the 1902 airfoil and significantly greater curvature over the aft half of the chord. Those properties cause the Flyer-indeed all Wright powered aircraft to 1910 - to have a relatively large negative zerolift pitching moment, which, with an aft c.g., produces the problems discussed in Sec. VII.

The large zero-lift pitching moment and the aft location of the c.g. dominated the longitudinal dynamics of the 1903 Flyer. Analyses and numerical simulations provide the best evidence we have for the sorts of dynamics the Wrights must have encountered with their 1903 Flyer. Culick and Jex ${ }^{41}$ and Jex and Culick ${ }^{43}$ reported the first results. With the use of wind-tunnel data acquired in subscale wind-tunnel tests ${ }^{39,44}$ both longitudinal and lateral dynamics of the Flyer, open-loop and closed-loop with a pilot exercising proportional control were calculated. Since that work, a test program with the AIAA full-scale replica ${ }^{45}$ has confirmed and extended the subscale results. Nearly all data required are available for carrying realistic analysis of the Flyer's dynamic behavior using well-known methods. ${ }^{46}$ Quantities not measured, notably the rotary derivatives and damping forces, are estimated with the simple formulas of aerodynamic strip theory. A thorough report of the more recent analysis has been prepared by Papachristodoulou and Culick. ${ }^{47}$ One detail is worth noting: For all of the Wright gliders and powered aircraft, 1900-1912, the virtual or apparent masses associated with acceleration of the air are significant for all rotational motions and is about $28 \%$ of the actual mass in heaving accelerationsfor the 1903 Flyer.

Figure 14 is a root locus plot for the pitch angle dynamics of the Flyer. As the preceding discussion has established, the open-loop (zero-gain) roots represent a lightly damped phugoid ${ }^{* * *}$ having a period about $5 \mathrm{~s}$ and a degenerate short-period oscillation and a stable and a divergent exponential, the latter having doubling time of approximately $0.6 \mathrm{~s}$. The locations of the open-loop zeros are dominated by the values of the static margin $\left(T_{\theta_{2}}\right.$, the high-frequency factor) and the damping forces and pitching moment due to changes in the forward speed ( $T_{\theta_{1}}$, the low-frequency factor).

The instability in pitch is illustrated by the simulation in Fig. 15 showing the exponential increase of pitch angle following a brief

*** Because the aircraft is unstable, this is not a true phugoid, and its period is not accurately estimated with the formula $2 \pi \sqrt{ }(\bar{u} / g)$. Etkin ${ }^{37}$ refers to this motion as the third mode of longitudinal dynamics. The Appendix is a brief explanation of this important characterization of an aircraft unstable in pitch. deflection of the canard. This motion may be interpreted equivalently as the response to a vertical gust striking the canard. The doubling time of roughly $0.5 \mathrm{~s}$, slightly longer than the average person's reaction time, can be controlled by a skilled pilot, as the Wrights demonstrated in 1903 and 1904. As an approximation to feedback (closed-loop)control, suppose that to maintain level flight the pilot exerts corrective deflection of the canard proportional to the difference between the observed pitch angle of the aircraft, for example, the orientation of the canard, and the horizon. For a gain of $4 \mathrm{deg}$ (of canard deflection for $1 \mathrm{deg}$ of error) the closed-loop roots are identified in Fig. 14. The response in pitch and the pilot's control input are shown in Fig. 16 for a commanded step change in pitch angle of the aircraft.

Note in Fig. 16 the oscillations of both canard deflection and pitch angle of the aircraft. The behavior of the angle $\delta_{c}$ of the canard is due to the pilot's attempt to reach the command angle of climb. Then control activity is reflected in the oscillation of pitch angle itself, representing a damped pilot-involved oscillation (PIO). Given the lightly damped oscillatory roots shown in Fig. 14 for $K=4$, the presence of the PIO is not surprising. Even though the Flyer is severely unstable in pitch, it can be controlled by a skilled pilot. The motion is described further by Culcik and $\mathrm{Jex}^{41}$ and Jex and Culick. ${ }^{43}$ It can be seen in films of the Wrights flying in 1909-1910.

\section{The Wrights Discover Lateral Dynamics}

The three lateral degrees of freedom are translation along the axis perpendicularto the plane of symmetry, rotation in roll, and rotation in yaw. It is the presence of two rotations that makes lateral motions seem somewhat more complicated than the longitudinal motions. The translational velocity is $v$, and the two rates are $p$ and $r$ in roll and yaw, respectively.

\section{A. Normal Modes for Lateral Motions}

For a rigid aircraft there are usually three distinct normal modes: the roll subsidence, the spiral mode, and the lateral or Dutch roll oscillation. All three generally have components of motions in the three lateral degrees of freedom, but some simplifications are possible and often give acceptably accurate results.

The roll subsidence is nearly a pure rolling motion that can be excited by a step change of aileron setting. Small yaw and lateral translational motions may be generated due to the action of lateral cross derivatives. In any event, the roll subsidence is heavily attenuated due to the large damping-in-roll provided by the wings.

A second mode, the spiral mode, also usually has behavior exponential in time. It is either lightly damped or weakly unstable. The spiral mode for the 1903 Flyer was seriously unstable due to the negative dihedral, causing the Wrights so much trouble that they eventually made the modifications necessary to stabilize the mode.

The third lateral mode is the lateral oscillation, which always involves contributions from the three degrees of freedom. It is most obviously a coupled yaw/roll oscillation but also involves oscillatory translational or slipping motions perpendicular to the forward motion. Usually the frequency of the lateral oscillation lies in the range where it is easily excited during flight through turbulent air or by appropriate periodic manipulation of the controls. Otherwise it is hardly noticeable in normal flight of conventional aircraft.

\section{B. The Wrights' Experience with Lateral Dynamics: 1901-1902}

It was Wilbur's observation of adverse yaw in 1901 that first caused the Brothers to pay attention to motions in yaw. Eventually they also noticed a slipping motion subsequent to rolling their aircraft, an observation confirming that they encountered the spiral mode.

When they returned for flight tests at Kitty Hawk in 1902, their new glider (Fig. $17 \mathrm{a}^{24}$ and Fig. $17 \mathrm{~b}^{26}$ ) was larger and heavier than the 1901 machine but had the same wing loading (0.84 psf). More significantly, it sported a fixed double vertical tail intended to compensate adverse yaw when the aircraft was rolled to turn.

During the first part of their flying season in 1902, the Brothers concentrated on learning how to turn. Because they were flying close to the slopes of the hills-they probably rarely reached altitudes greater than a wingspan or two- they never completed, or 


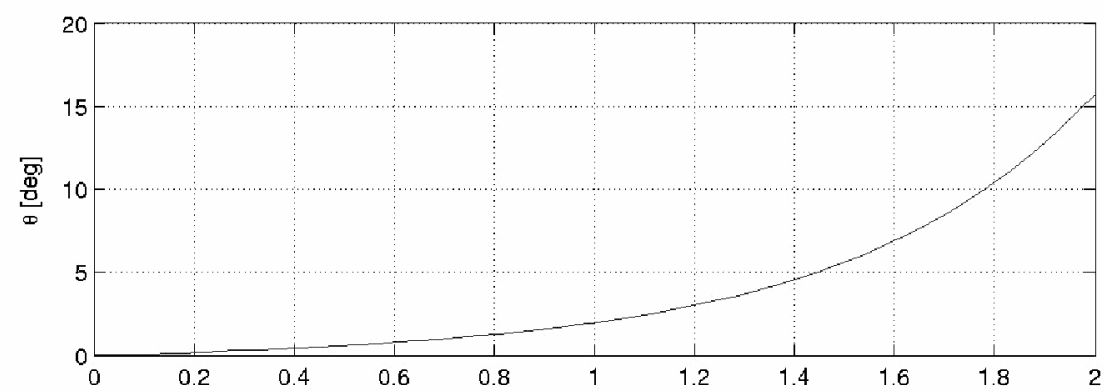

a) Pitch attitude angle

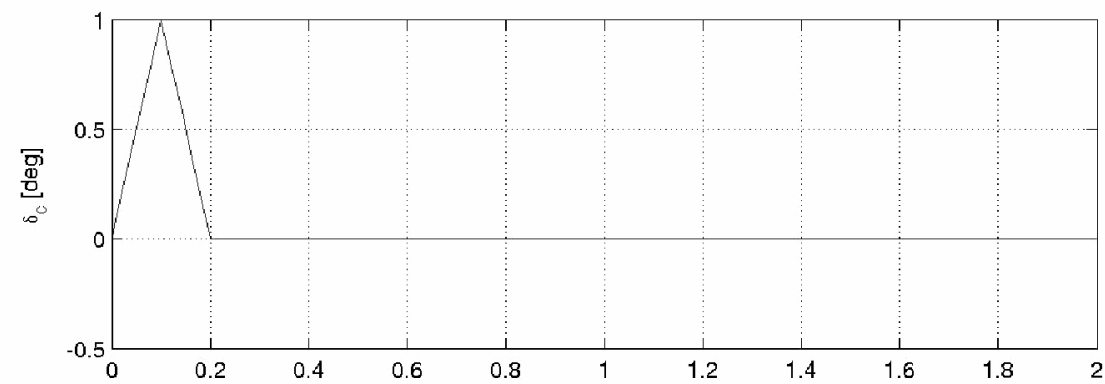

b) Angle of canard deflection

Fig. 15 Open-loop time response of the 1903 Flyer to a triangular disturbance of the canard setting.

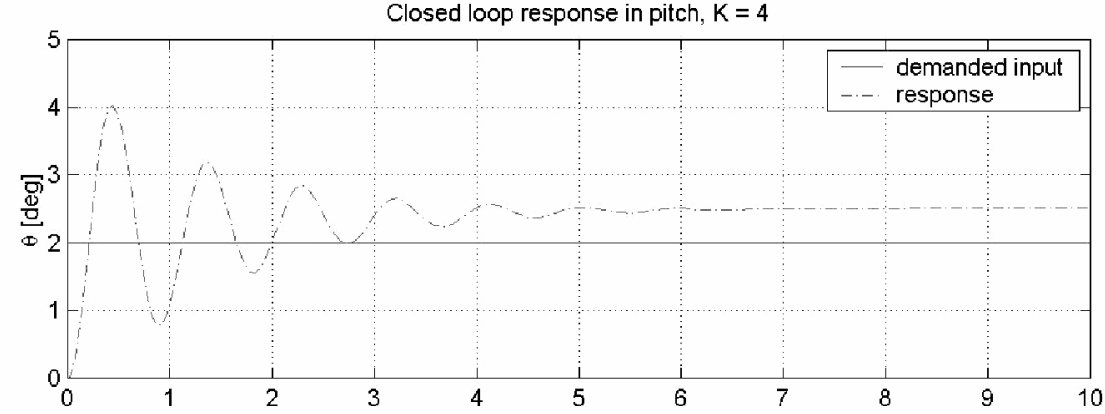

a) Pitch attitude angle

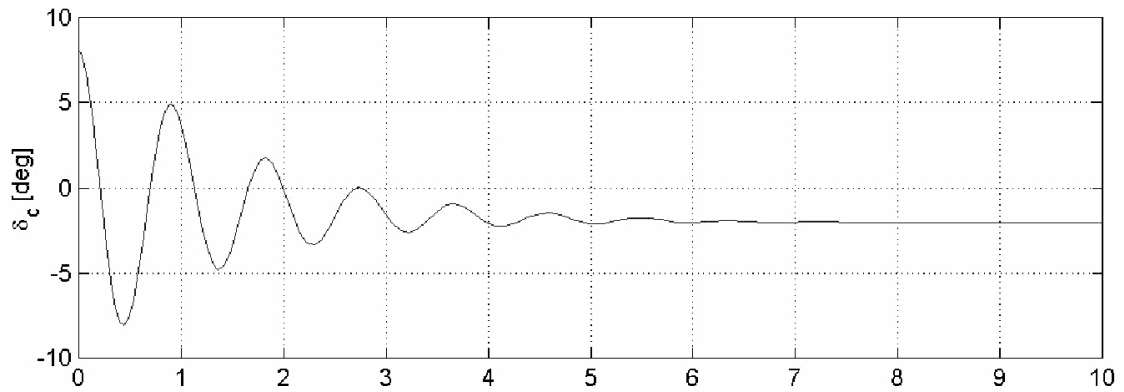

b) Angle of canard deflection

Fig. 16 Closed-loop (piloted) time response of the 1903 Flyer to a step command input of pitch angle.

even attempted, full circles. Rather, it seems clear that they were trying to figure out the basic mechanics of the turn partly to learn how to maintain straight flight in the presence of wind gusts. They encountered two problems that demanded small changes of their design. Or perhaps they were two manifestations of the same problem, caused partly by adverse yaw.

During the early gliding tests, both Brothers encountered an annoying form of the response to gusts. Up to this time, all of the gliders had positive dihedral effect, following Cayley's idea to provide intrinsic stability to disturbances in roll. If one wing drops or-what is the same aerodynamically-the aircraft is exposed to a side gust, then positive dihedral causes the airplane to right itself in the sense indicated in Fig. 18. In particular, for example, a gust from the right causes the airplane to roll to the left, that is, the left wing is rotated downward. That was troublesome to the Wrights for the following reason.

The Wrights were gliding down a slope into the wind. Most gusts occurred in the direction of the wind, that is, up the hill. When they attempted to turn, or for some other reason they were not flying directly into the wind, a gust would cause the uphill wing to drop (positive dihedral effect), occasionally striking the slope. That happened sufficiently often that the Brothers decided to truss the wings for negative dihedral (also called "anhedral"), with the tips being lower than the center.

With or without anhedral, the glider having fixed tail also several times exhibited a second problem associated with adverse yaw. As a gentle turn, having relatively small roll angle, was being corrected to level flight, the outer wing of the turn dropped and struck the 


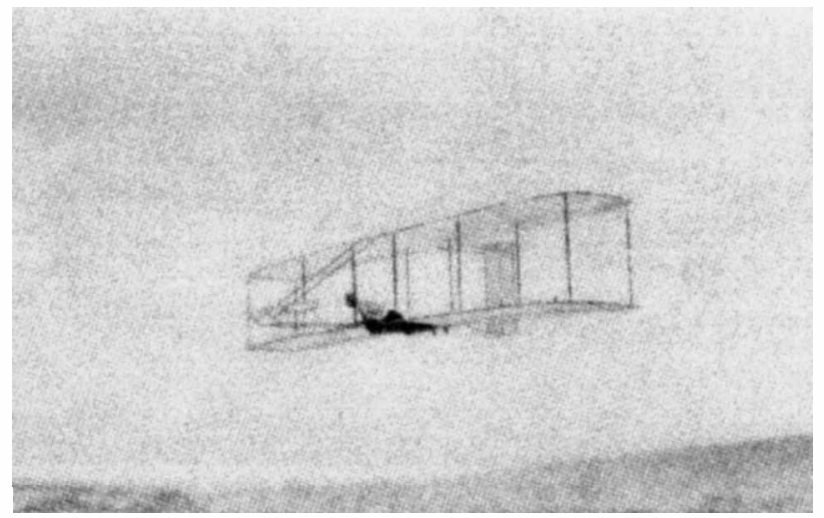

Fig. 17a First version of the Wrights' 1902 glider (McFarland, ${ }^{24}$ Plate 41).

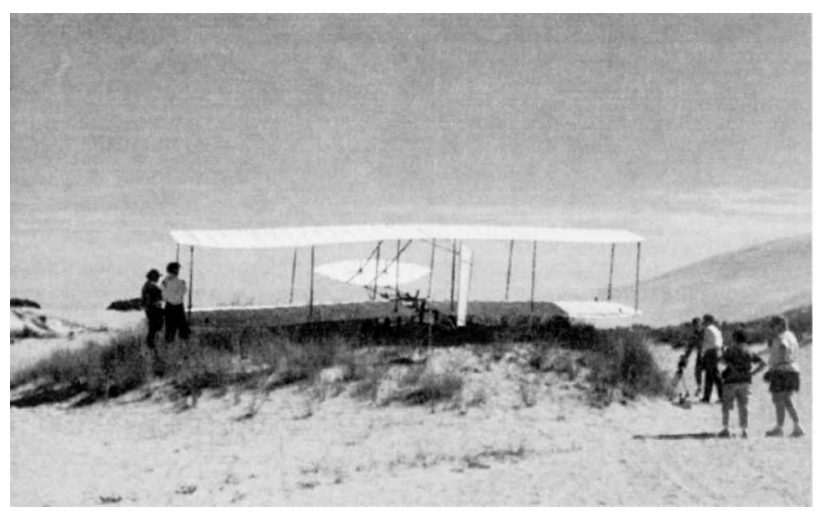

Fig. 17b Recreation of the 1902 glider (Engler 2001). ${ }^{26}$

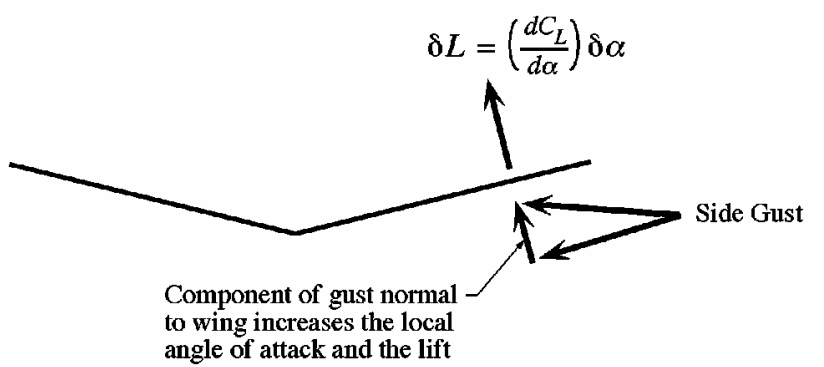

Fig. 18 Dihedral effect.

ground. The Brothers called this event "well-digging." Wald ${ }^{48}$ has best explained the cause of the problem. Suppose the glider is turning to the left, for example, and to correct the turn the wings are warped, with the trailing edge of the left wing warped downward to increase its lift and stop the turn. Because of adverse yaw, the wing is slowed, the lift is initially reduced, and the wing actually drops. If the glider is sufficiently close to the ground, the tip of the wing would strike the sand and serve as a pivot point for the glider to swing to rest.

In 1902, the new vertical tail, because it provided directional stability, did help the aircraft turn. However, also because it was fixed, it had a serious shortcoming: It was effective only if the aircraft had translational motion laterally, that is, slipping. When a turn was initiated, adverse yaw swung the aircraft such that the lift (to the side) generated by the tail would correctly compensate the swinging motion. However, apparently the correction was too large under some circumstances, causing the glider's nose to swing too far into the turn, which is the beginning of motion that we now know as the spiral mode. Whatever the cases may have been, the absence of any control of the yaw moment generated by the vertical tail had unacceptable consequences.

Orville (McFarland, ${ }^{24}$ p. 470 ) later testified in a deposition that their glider having "cathedral angle [anhedral] with fixed rear vertical tail and adjustable wing type was the most dangerous...." The negative dihedral caused the spiral mode to be seriously unstable so that any attempted turn would lead to a crash unless corrected very quickly.

Those unsatisfactory results with the glider having fixed tail convinced the Brothers of the need to modify their design. It was Orville who suggested that the vertical tail be made controllable. In the interest of simplifying the pilot's workload, Wilbur proposed connecting the rudder control to the warp control. From then until September 1905, the Wrights flew their aircraft with roll and yaw controls interconnected. They were the last designers to connect roll and yaw controls until Fred Weick invented the Ercoupe in the late $1930 \mathrm{~s}$

Not fully recognizing the consequences of giving an unstable spiral mode, the Wrights retained the negative dihedral until November 1904. They finally realized that it was causing problems when they attempted turns and removed the anhedral in early November.

After installing anhedral and a movable vertical tail, the Brothers spent the remainder of the 1902 season learning how to fly their glider. At most, they seem to have attempted only gentle turns. They continued that kind of practicing for two months in 1903 while they prepared the powered aircraft. It seems a fair assessment to characterize this period of their flying as a process of learning how to fly more-or-less straight and level in the presence of disturbances or gusts. They did not expose any new problems of flight dynamics.

In that context, the first powered flights were really powered and sustained level gliding flights following takeoffs. The 1903 Flyer was larger than the 1902 glider (span $40 \mathrm{ft} 4$ in. compared with $32 \mathrm{ft}$ 1 in.) and heavier $(750 \mathrm{lb}$ compared with $257 \mathrm{lb}$ ) and had wing loading increased from 0.84 to 1.47 psf. Moreover, the 1903 airplane was much more unstable than the 1902 glider. Hence, the 1903 airplane surely offered more difficult handling qualities, but with only four straight flights, the Brothers did not report new dynamic problems. If unexpected dynamics did appear, they were likely not easily identified, being obscured by the Brothers' vigorous efforts to keep the airplane in the air under very difficult windy conditions. Surely the sheer excitement of executing the first powered flights must also have blunted the observational powers even of the Wright Brothers.

\section{Lateral Dynamics of the $\mathbf{1 9 0 3}$ Flyer}

That the 1903 Flyer had a serious instability in pitch has been widely discussed and argued about. Little attention has been paid to the lateral dynamics, the chief exceptions being the analyses by Culick and Jex, ${ }^{41}$ by Jex and Culick, ${ }^{43}$ and most recently by Papachristodoulou and Culick. ${ }^{47}$ Mainly because of the negative dihedral effect and low directional stability (a consequence of the small vertical tail volume), the spiral mode had a relatively short doubling time, approximately $2 \mathrm{~s}$, and a weakly damped Dutch roll oscillation.

Combination of the lateral instability with the pitch instability makes flying the 1903 Flyer an order of difficulty greater than riding a bicycle. The level of pilot handling qualities is not apparent from the analyses described here; it is a characteristic that can be understood only with three-dimensional simulations. That was accomplished as part of a project carried out two years ago by six students at the Air Force Test Pilot School ${ }^{49}$; the software was prepared by engineers at Veridian, Inc., for a ground simulation and for the Learjet-24 Variable-Stability In-Flight Simulator Test Aircraft. The pilots found that flying the aircraft was made more difficult due to the attention demanded by the two instabilities having significantly different doubling times $(0.6 \mathrm{~s}$ in pitch and $2.0 \mathrm{~s}$ laterally). Thus, for example, concentrationon controlling the pitch instability, which requires constant attention, may lead to losing control of the spiral mode.

Understandingthe natural lateral motions and controlled response of the Flyer is, therefore, particularly helpful if one intends to fly a recreation of the airplane. Performance in a turn is a good way to assess the problem. The Wrights were first to understand the correct method for turning an airplane: deflection of wing warp (or ailerons) for a short time to give a finite roll angle, use of rudder to provide the required yaw rate in body axes, and, if necessary, application of power or change of pitch attitude to maintain safe airspeed above stall. Here we ignore the last and assume constant speed. Figure 19 shows the uncontrolledresponse of the Flyer to 10 deg of wing warp 


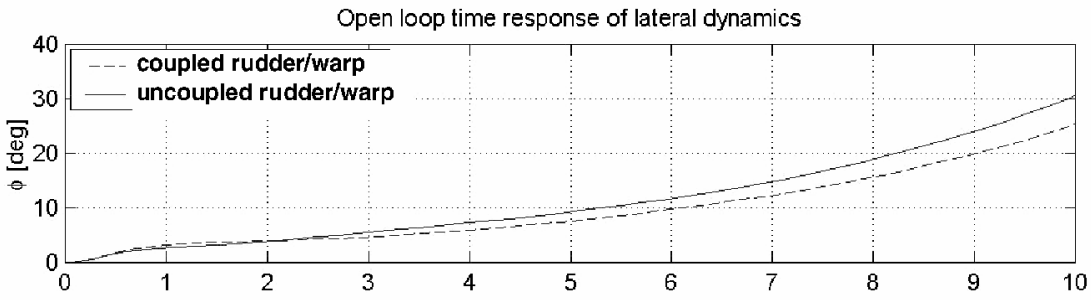

a) Bank angle

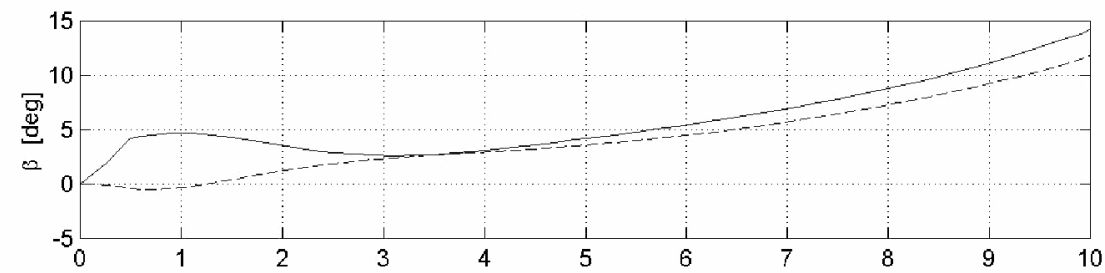

b) Sideslip angle

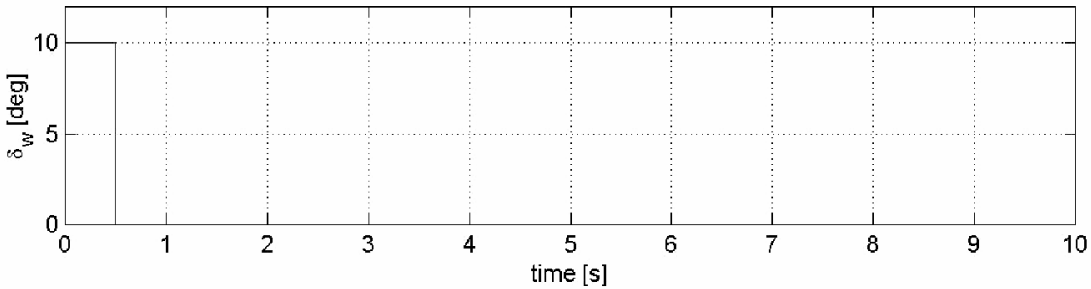

c) Warp angle

Fig. 19 Open-loop time response of bank angle and sideslip following an impulse of wing warp (1.0 deg.s).

Root locus for lateral motion, warp alone

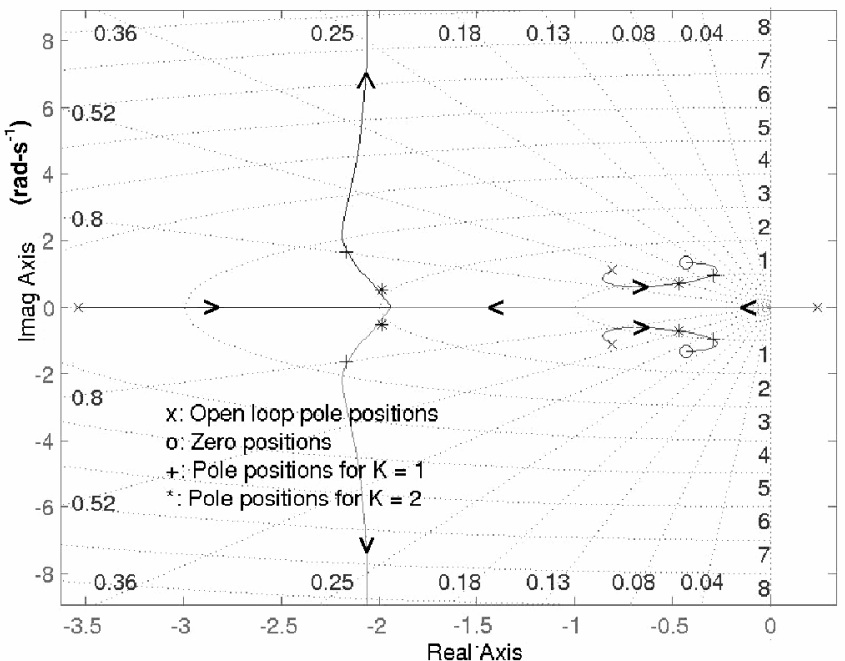

a) Fixed rudder

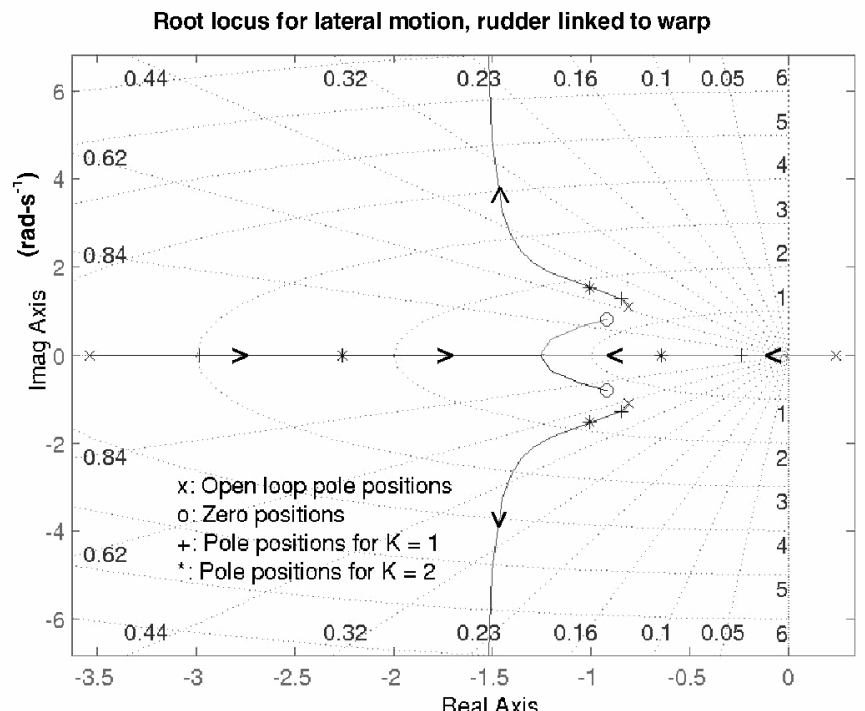

b) Linked warp and rudder

Fig. 20 Root loci for lateral motions of the Wright 1903 Flyer, pilot control; warp deflection proportional to roll angle error, gain coefficient $K$.

applied for $\frac{1}{2}$ s. To execute a turn, the pilot must actively compensate the lateral instability.

When the Wrights added their vertical tail to their 1902 glider, they chose first to fix the surface, but soon linked its deflection to the wing warping. The 1903 Flyer had the warping and rudderdeflection linked. We examine the two cases of fixed and linked with the root locus shown in Fig. 20, prepared with aerodynamic data collected in the Los Angeles AIAA Project. For both cases, we assume that the pilot exercises control, that is, warp deflection, proportional to the error observed between commanded, that is, desired, and actual bank angle.

Execution of a turn is analyzed by specifying the desired angle of bank (here $10 \mathrm{deg}$ ), the input being a ramp followed by a step.
Figure 21 shows the time responses for the two cases of fixed and linkedrudder. The results are very different.If the rudder is deflected, the aircraft quite smoothly enters the steady turn, albeit with error in bank angle on the timescale shown. The correspondingroot locus (Fig. 20b) shows the reason. Loop closure causes the roll subsidence and spiral mode to coalesce, forming a lightly damped pure roll oscillation having very long period, roughly $6 \mathrm{~s}$. Simultaneously the frequency of the Dutch roll oscillation is slightly increased but has much greater damping.

In contrast, if the rudder is fixed, the spiral mode combines with part of the Dutch roll to form a roll oscillation similar to that arising when the rudder is fixed. The remainder of the Dutch roll combines with the roll subsidence to form a new mode, a sort of wallowing 


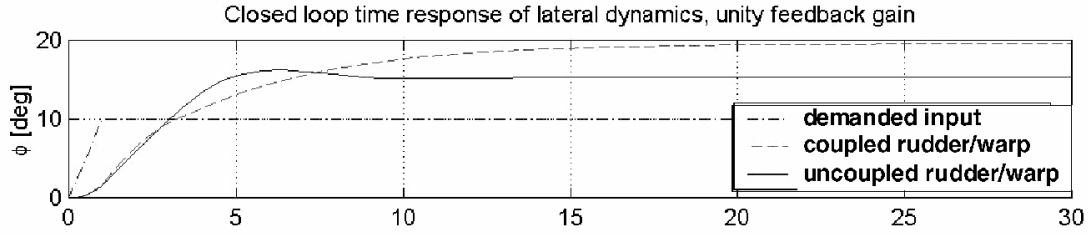

a) Bank angle

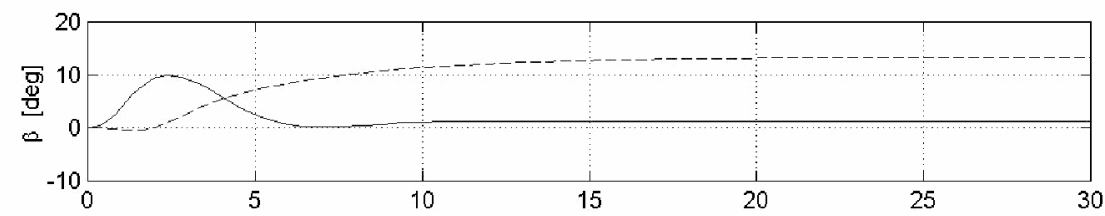

b) Sideslip angle

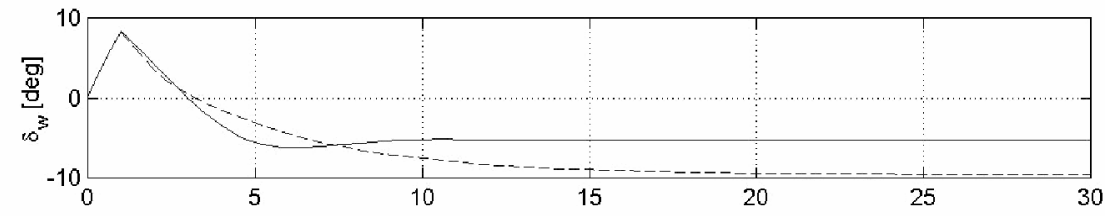

c) Warp angle

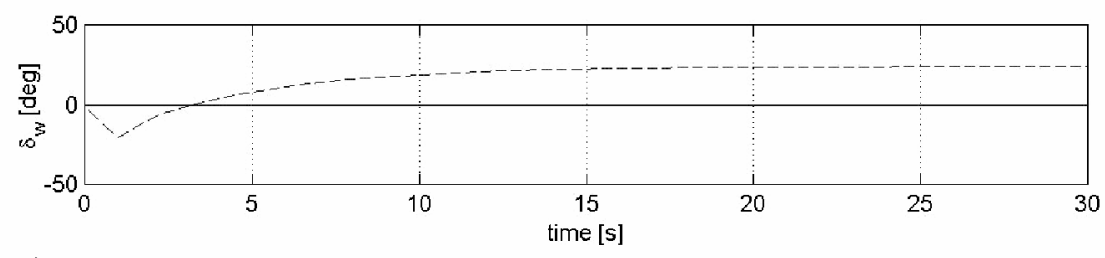

d) Rudder angle

Fig. 21 Closed-loop (piloted) time responses of the 1903 Flyer for a 10-deg banked steady turn.

motion composed of relatively large oscillations of bank angle and sideslip, due to the anhedral and uncompensated adverse yaw. It is difficult to control and, paired with the PIO in pitch, produces unacceptable pilot handling qualities.

The pilots in the project with the Air Force Test Pilot School found this behavior just described and concluded that the Flyer is nearly unflyable if the rudder is fixed. An alternative scheme is to use conventional three-axis control, the pilot operating the canard, wing-warp, and rudder independently.However, Wilbur made a wise choice to link the roll and yaw controls. His reasoning, supported by the test pilots' experience, is that the pilot's workload is unacceptably high when the lateral controls require independent operation.

\section{More Trouble with Dynamics: 1904}

The Wrights' program became a different story in 1904. They began with a new airplane having the same design as the 1903 Flyer but with a larger engine producing about 20-25 hp compared with the 12-16 hp of the earlier aircraft. From the beginning of the 1904 tests, the Brothers had trouble. In the light or calm winds and higher density altitude ${ }^{19}$ takeoffs were difficult and often failed, even with a longer takeoff rail. Orville stalled the machine shortly after one of his first flights, and Wilbur soon imitated him. They first used the term stall in their report of those flights.

More distressingly, they continually fought the pitching undulations that, though unreported, were likely present also in the 1903 flights. In an effort to correct the problem, they moved the engine, its water tank, and the pilot aft, exactly the wrong direction. The records are not complete, but according to the flight log compiled by Renstrom, ${ }^{50}$ the Wrights made only two flights with the aft c.g. Wilbur noted in a letter to Chanute on 17 July that "the result was not satisfactory," and the Brothers restored the original configuration.

They made no further changes to the airplane in 1904, but they did devise their catapult apparatus to ease their takeoff problem (Fig. 22). ${ }^{24}$ They were continually forced to cope with the dynamics of taking off. Many trials ended in minor crashes before flying speed was reached. Even when takeoff was successful, it seems that they were always flying very close to the stalled condition. Although

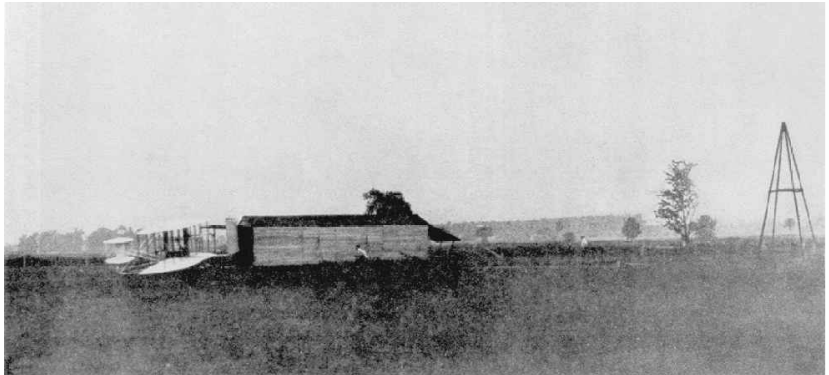

Fig. 22 Wrights' catapult launching apparatus at Hoffman Prairie, August 1904 (McFarland ${ }^{24}$ ).

they knew they had to maintain some minimum speed, in the vicinity of $27-28 \mathrm{mph}$, the fact that they really did not understand the phenomenon of stalling and why it occurred probably hindered their progress. They seem not to have been aware that the canard could stall as well, with consequent loss of control power in pitch.

Thus, with an airplane they knew to be unstable but controllable in pitch, always plagued with the familiar pitch undulations, the Wrights pressed on to learn how to fly circles. Wilbur flew their first complete circle on 20 September 1904, a grand achievement with the 1903 design. As they continued practicing turns, both Brothers encountered a new serious problem that they characterized as "unable to stop turning" (McFarland, ${ }^{24}$ p. 457), identifying those flights sometimes terminated by crashes. Evidently the cause was one now familiar: stalling of the inner wing of the turn due to its slower speed and higher angle of attack. The Wrights sensed the cause and correctly eased the problem by adding seventy pounds of steel ballast to the canard, a move that reduced the amplitude of the pitch undulations and also caused them to fly faster.

Moreover, they also correctly concluded that the anhedral was causing them difficulties. Nowhere do they specifically mention any feeling that the airplane seemed to have a tendency to tighten turns, but that was surely a factor. In a turn, the presence of their unstable 


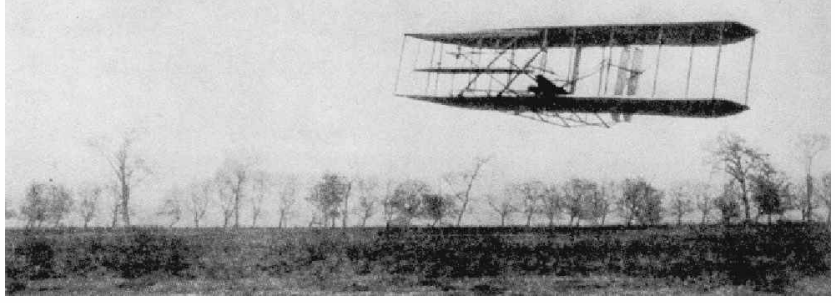

Fig. 23 Flyer on 16 November 1904: 1903 design with a larger engine and no anhedral (McFarland $\left.{ }^{24}\right)$.

spiral mode was bound to be felt because of its short $(\sim 0.8 \mathrm{~s})$ doubling time. In late October, the Brothers finally removed the anhedral (Fig. 23). ${ }^{24}$ That was the airplane for their last tests of 1904.

\section{1905: Flight Tests Lead to the Final Design of a Practical Airplane}

In a court deposition (Wrights vs Herring-Curtiss), Wilbur (McFarland, ${ }^{24}$ p. 469) explained clearly that, while they had progressed considerably in 1904, the Brothers were still left with a puzzle: "on a few occasions, the machine did not respond promptly (to action taken to restore lateral balance) and the machine came to the ground in a somewhat tilted position." That is, the pilot could not cause the transition from a turn to level flight and the aircraft crashed. The airplane was unreliable and certainly not yet a practical machine.

The Wrights eventually solved the puzzle when they discovered the correct flying technique, in the last days of September 1905. Before they reached that point, they made some important modifications in their design, relating to both lateral and longitudinal dynamics.

When they began flying again in June 1905, the Brothers still had essentially the 1903 design, but with some detailed structural changes for improved strength and a larger engine, now producing more than $30 \mathrm{hp}$. For some reason, not documented, they reinstalled a small amount of anhedral. They also added small vertical vanes to the canard that came to be called "blinkers." Those surfaces mainly reduced the directional stability and in the absence of explanation it is not clear why the Wrights thought they would help ease their steering problems; evidently they believed they would reduce the problem of slipping when the aircraft has a lateral translational velocity. That in turn reduces a roll motion, in a sense depending on the dihedral effect (positive or negative). Perhaps the most important consequence was that the blinkers increased the damping in yaw and, hence, helped pilot control in yaw.

On 14 July, Wilbur noted that at a higher flight speed he had trouble once again with the undulationsin pitch and crashed, causing considerable damage to the canard. When they made repairs, the Brothers increased the area of the canard by about $73 \%$ and moved its hinge line forward from about $6 \frac{1}{4}$ to $1-10 \frac{1}{4} \mathrm{ft}$. That is an interesting modification, which reflects again the Wrights' lack of understanding of stability and, probably, their central concern for control. The larger volume of the canard causes the NP to lie farther forward, a destabilizing effect.

On the other hand, the larger canard volume increases the damping in pitch, which gives substantial improvement in controllability by reducing the frequency and amplitude of the oscillations. Also, the more forward placement of the canard reduces a destabilizing influence of upwash from the wing. Recent tests with ground simulations ${ }^{49}$ have confirmed the advantage of increased damping in pitch. Technically, it causes the maneuver point to move aft, a favorable result for controlling accelerated motions, including undulations. The Wrights clearly found that to be a good modification, although in their 1907-1909 models the canard was made smaller and moved farther forward, a $3.8 \%$ decrease in tail volume from the value in 1905 . Nothing in their diaries gives explicit reasons for the details of those changes, but it is a reasonable guess that they experienced improved controllability in pitch due to the slight reduction of the instability.
While those repairs and modifications were being made, the Brothers made some measurements of the center of pressure on their airfoil, the first such data they (or any others) had taken (Fig. 12). Apparently those tests were done in direct response to the July crash. However, there is no evidence in their diaries $\left(\mathrm{McFarland}^{24}\right.$ ) about their interpretation of their results or what influence the tests may have had on their design changes. Their decisions about changes in the geometry affecting behavior in flight, and their interpretations of the consequences, continued to be restricted by their inattention to the details of moments acting on the aircraft.

When they modified the canard, they also enlarged the vertical tail. They had finally concluded that the tail was too small to give the control they required. From 1903 to the final design in 1905, the tail area and the distance between the wing and the tail were increased. The increase of dimensionless tail volume gave comparable increases in the directional stability and control power.

Installation of the larger vertical tail initially caused a handling problem. Wilbur commented that Orville's first flight with the new tail was "a very comical performance" (McFarland, ${ }^{24}$ p. 507). Possibly the difficulty arose because the hinge line was too far aft, behind the center of pressure which for a flat surface is approximately at the quarter chord. No change was made at that time, but in the 19071909 machines flown publicly, the vertical tail was hinged at the leading edge.

For the remainder of the 1905 season, all of September and for the first two weeks of October, only minor structural changes were made; the Brothers concentrated mainly on learning to turn. On 7 September Wilbur flew four circles consecutively, but then two days later, with larger propellers installed, he stalled the airplane twice. Again on 12 September, he stalled while turning, and on 15 September he was "unable to stop turning" (McFarland, ${ }^{24}$ p. 511). A week later they removed the anhedral they had been keeping since the beginning of the season, an indication that they were bothered by slipping in turns.

On 26 September, Orville executed 16 circles in one flight, remaining aloft $18 \mathrm{~min}$ until his fuel supply was exhausted. The Brothers' performance remained erratic, however. On the following day, Wilbur noted that the "machine at low speed could not be stopped from turning." On the 29 September, Wilbur made 14 circuits in $19 \mathrm{~min}$, but on 3 October he was "unable to stop turning" (McFarland, ${ }^{24}$ p. 513). The last was a mistake he understood, because on 28 September he finally isolated the source of the problems both he and Orville had been having: failure to maintain sufficient speed while turning, causing the inner wing to stall. They had been fighting what remains, even a century later, a cause of many accidents: stall/spin out of a turn. Wilbur explained the matter as well as anyone could today (McFarland, ${ }^{24}$ pp. 520-521):

.. When it was noticed that the machine was tilting up and sliding toward the tree, the operator then responded promptly to the lateral control. The remedy was found to consist in the more skillful operation of the machine and not in a different construction. The trouble was really due to the fact that in circling, the machine has to carry the load resulting from centrifugal force, in addition to its own weight, since the actual pressure that the air must sustain is that due to the resultant of the two forces. The machine in question had but a slight surplus of power above what was required for straight flight, and as the additional load, caused by circling, increased rapidly as the circle became smaller, a limit was finally reached beyond which the machine was no longer able to maintain sufficient speed to sustain itself in the air. And as the lifting effect of the inner wing, owing to its reduced speed, counterbalanced a large part of the increased lift resulting from the greater angle of incidence on that wing, the response to lateral control was so slow that the machine sank to the ground, usually before it had been brought back to the level again.... When we had discovered the real nature of the trouble, and knew that it could always be remedied by tilting the machine forward a little, so that its flying speed would be restored, we felt that we were ready to place flying machines on the market.

With their identification of the stall/spin problem and Wilbur's discovery of its solution, the Wrights announced they had a practical airplane. They ceased flying to turn all of their efforts to selling 


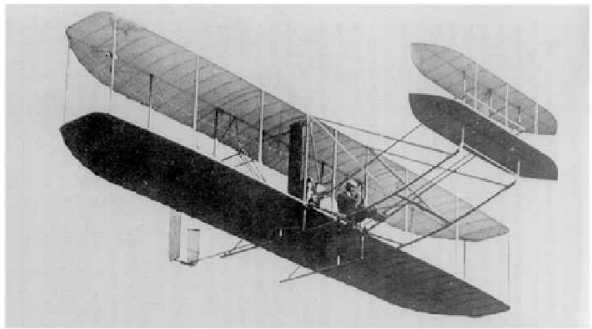

1908

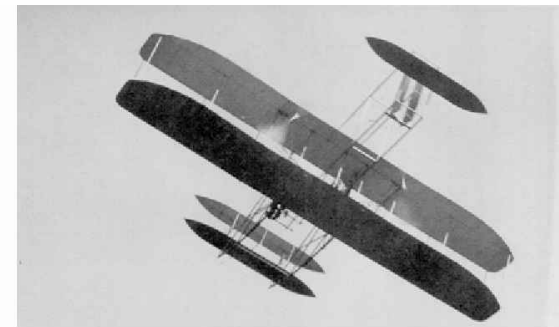

1910

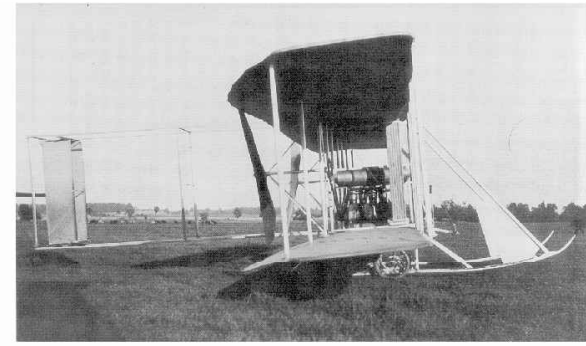

1911

Fig. 24 Transition from canard to aft tail.

their invention, another interesting story quite apart from technical matters.

\section{The Wrights' Transition from Canard to Aft Tail}

Wilbur initially settled on his canard configuration to avoid (he expected) the inadequate pitch control that Lilienthal had with his aft tail. Combined with the concentration of weight in the biplane cell, the canard presents a very difficult problem of designing for trim and stability. It was difficult to shift the c.g. far enough to give a positive static margin. The choice of airfoil for the wing then becomes a crucial matter nearly as important as the location of the c.g. An airfoil having a large negative zero-lift moment may give an aircraft that has a stable moment curve but cannot be trimmed, or can be trimmed but has an unstable moment curve. Moreover, in the second case, the trim condition may require lift from the canard that cannot be reached because the surface already stalls at a lower angle of attack. In practice, there are really only two certain ways out of this situation: Use a substantially different airfoil, even one having a reflexed camber line or change the configuration from canard to aft tail.

The Wrights learned from flight tests in 1904 some of the nasty consequences of their 1903 design. They were severely handicapped in understanding the problems they discovered because they were not aware of methods based on analyzing the moments acting on the aircraft in flight. Moreover, neither experimental nor theoretical investigations had progressed to the stage where anybody could understand the dependence of aerodynamic pitching moment on the shape of the camber line. All in all, then, the state of the art (which in fact had been developed by the Wrights themselves) was such that it was difficult for them to understand any technical reasons to justify changing their canard design.

No other designers contemporary with the Wrights suffered the same commitments to the canard. The French in particular were not so concerned with control as the Wrights were, and so they did not share the same fear of the aft tail. In fact, because it was Pénaud's tail, the French for the most part were biased, if not even prejudiced, to that configuration. As a result, the Wrights sought a controllable airplane, even if unstable, and they got it; the French sought an intrinsically stable airplane design, and got it, but at the expense of paying too little attention to the fundamental problem of control. Ferber ${ }^{51}$ generated French interest beginning in 1902 with crude copies of the 1901 glider. While he continued to use the canard surface, problems with his first powered aircraft caused him to add a Pénaud aft tail. That is the origin of the configuration having both canard and aft tails used by several pioneers in France and adopted also by Curtiss in the United States.

After their two-year flight-test program, the Wrights had finally gotten rid of their lateral instability. Their observationsdemonstrated repeatedly that the unstable spiral mode interfered with circling - so they removed the anhedral initially installed to solve a problem peculiar to their glide tests close to the ground. Their tests also showed that by carrying ballast to move the c.g. forward the intensity of the pitch instability was reduced. Geometrical restrictions raised serious obstacles to making their canard stable, and they were satisfied with an aircraft unstable in pitch, but controllable.

Following the Wrights' first public flights in 1908, when their contemporaries finally grasped the significance of control, advantages of conventional configurations became increasingly apparent. The Wright aircraft were undoubtedly more difficult to learn to fly, a distinct shortcoming at the time when the new businesses of flying schools and aircraft manufacturing were growing rapidly in many countries of Europe. Conventional aircraft slowly gained a reputation for being safer. The Wrights were effectively pressured to relax their commitment to their canard design. Possibly at the suggestion of a German customer, they relented. Their first step was simply to add a fixed horizontal tail to their existing design, in 1910. The improvement in handling qualities must have been immediately evident. Few pictures of the airplane exist (Fig. 24), ${ }^{24}$ and within a year the Wrights removed their canard surfaces. That ended their use of the configuration that had been their invention and had served them well for a decade. Despite their commitment to that form of the airplane, original with them, the Wrights did not try to patent it. ${ }^{\dagger \dagger}$ The basis for their patent, granted in 1906 and never broken, was their two-axis control of lateral motion, in general, not for their particular aircraft design, and not including pitch control.

It is certainly true that if not the Wrights, somebody else would have invented the airplane in the early years of the 20th century. Bleriot was closest to having all of the practical pieces in place by 1908 - except for three-axis control, which he learned from the Wrights. In fact, Bleriot (see Crouch ${ }^{52}$ and Gibbs-Smith ${ }^{17}$ ) owes an earlier debt to the Brothers, for their achievements motivated Ferber to initiate the "rebirth of aviation in Europe" (Gibbs-Smith ${ }^{17}$ ),

\footnotetext{
${ }^{\dagger \dagger}$ Subsequent to the Wrights it became accepted practice, still continued, to patent an aircraft configuration (external geometry).
} 


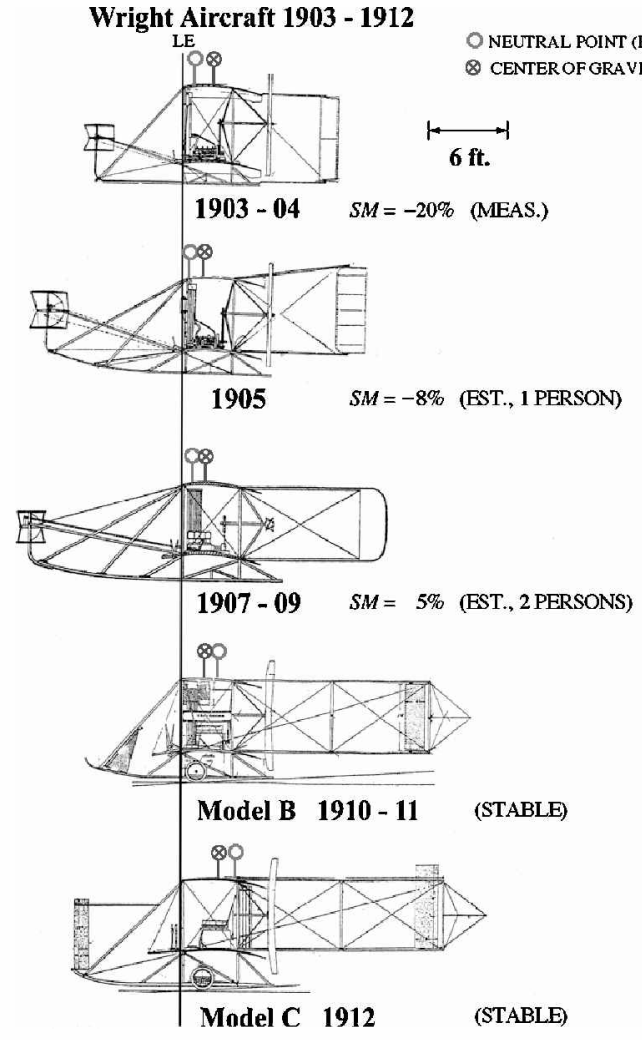

Fig. 25 Summary of Wright aircraft, 1903-1912 (drawings reproduced from McFarland, ${ }^{24}$ pp. 1188-1200).

the activity in France that attracted Bleriot to the problem of mechanical flight.

Bleriot's approach of largely uninformed trial and error contrasts stunningly with the Wrights' systematic research and development program centered on the evolution of one design. (His successful monoplane that was his first real success, later crossing the English Channel, was his 11th design.) Everybody began with the same history and known results at the end of the 19th century, but the Wrights brought with them the revolutionaryidea of roll control; willingness gained from their experiences with bicycles, to accept an unstable, but controllable, machine; and especially their own original style, now recognized as a modern research and development program.

That style was central to the ability of the Wrights to develop their airplane in such a relatively short time without benefit of the understanding and guidance later provided by theories of aerodynamics and flight mechanics. Had those theories been developed earlier, it seems certain that the Wrights would have avoided the problems caused by their highly cambered airfoil and their canard configuration. Their systematic progress to solutions to those problems is clearly shown by the sequence of side views of their aircraft (Fig. 25). ${ }^{24}$

The summary given in Fig. 25 (McFarland $\left.{ }^{24}\right)$ is really a pictorial progress report of a successfulflight-test program. While the biplane cell, notably the airfoil, remains practically unchanged, and most of the weight is concentrated between the wings, the change of the size and location of the secondary horizontal surface finally produced a stable aircraft in 1911. The forward displacement of the c.g. from 1903 to 1905 was important but insufficient to provide longitudinal static stability.

At the beginning of their program, the Wrights estimated that in all his gliding tests, Lilienthal had been in the air perhaps $5 \mathrm{~h}$, too little, they felt, to reach his goal of having a powered flying machine. They set out to do better, the chief reason they selected Kitty Hawk, a place known to have steady strong winds during most of the times they planned to be there. In fact, the Brothers themselves accumulated between them less than $6 \mathrm{~h}$ gliding experience from 1900 to 1903.

What is truly surprising is that by the time in October 1905 they were satisfied they had their practical aircraft, the two together had attempted about 150 takeoffs, of which 115-120 were completed but only 100 led to successful landings. In toto they had less than $6 \mathrm{~h}$ experience with their powered aircraft, giving them a total of about $12 \mathrm{~h}$ flying experience between them when they finished their research and development program. What a testament to their ability to observe and act accordingly to improve their design.

A modern student pilot has perhaps $8-12 \mathrm{~h}$ of dual flying experience before soloing. The Wrights both learned how to fly and invented their airplane with combined flying time not much longer than a good night's sleep.

\section{Concluding Remarks}

As part of the international celebrations accompanying the centenary of the Wrights' first powered flights, several groups in the United States are constructing flying recreations of the 1903 Flyer. The best known at this time are those led by Engler in Dayton, Ohio (www.first-to-fly.com); Hyde in Warrenton, Virginia (www.wrightexperience.com); Young working with the Science and Space Museum in Richmond, Virginia; and the AIAA, Los Angeles Section, Wright Flyer Project (www.wrightflyer.org). The first three aircraft are intended to be accurate replicas of the original Flyer as best as can be determined from the available information. Only Hyde, under sponsorship of the Experimental Aircraft Association and with generous private funding, plans to fly at Kitty Hawk on the anniversary day, 17 December 2003. His aircraft is a meticulously accurate replica, including engine and possibly fuel. Following flights of a replica of the 1902 glider, current plans apparently include one takeoff from a replica of the original $60-\mathrm{ft}$ rail, placed accuratelyin the sand at Kitty Hawk. Success will requireclose replication of the original flight conditions, steady winds of 25-27 mph. It is an extremely difficult and ambitious goal. How difficult has been demonstrated by Kellett (reported in AOPA Magazine ${ }^{53}$ ), who seems to have had only partial successes getting his accurate replica off the ground, the only known attempts. The aircraft is seriously underpowered, and to take off in winds roughly $75 \%$ of cruise speed is rarely attempted with any airplane. In a statement to the Associated Press in January 1904, the Wrights themselves remarked:

Only those acquainted with practical aeronautics can appreciate the difficulties of attempting the first trials of a flying machine in a twenty-five mile gale. As winter was already well set in, we should have postponed our trials to a more favorable season, but for the fact that we were determined, before returning home, to know whether the machine possessed sufficient power to fly, sufficient strength to withstand the shocks of landings, and sufficient capacity of control to make flight safe in boisterous winds, as well as in calm air.

The AIAA Flyer Project has different goals. Formed 25 years ago with $\$ 20,000$, an insurance award for loss of a previous replica, the project has had two primary goals: 1 ) build a full-scale accurate replica of the 1903 Flyer to be tested in the $40 \times 80$ wind tunnel at NASA Ames Research Center and 2) build and fly a recreation of the 1903 Flyer capable of repeated flights, by several pilots, to give publicly an accurate impression of the Wrights' first flights. Throughout the project, the participants have prepared publicly available documentation and have been actively engaged in educational activities. The first goal has been achieved; the aircraft was on display in the building housing the Western Region Headquarters of the Federal Aviation Administration, until September 2002 , when it began an 18-month nationwide tour sponsored by the AIAA.

To achieve the second goal requires an aircraft slightly modified from the original design, but it must meet the vague requirement of stand-off scale such that from a distance of a couple of wingspans, even an expert will be hard pressed to detect the modifications. That constraint has been part of the motivation for the two subscale wind-tunnel test series and the full-scale tests, as well as for the investigations of flight mechanics reported in this paper. The comprehensive analysis reported by Jex and Culick ${ }^{43}$ and Papachristodoulou and $\mathrm{Culick}^{47}$ serve as the basis for making minimal changes of design to give an aircraft less unstable than the 1903 Flyer and with improved flying qualities. Understanding 


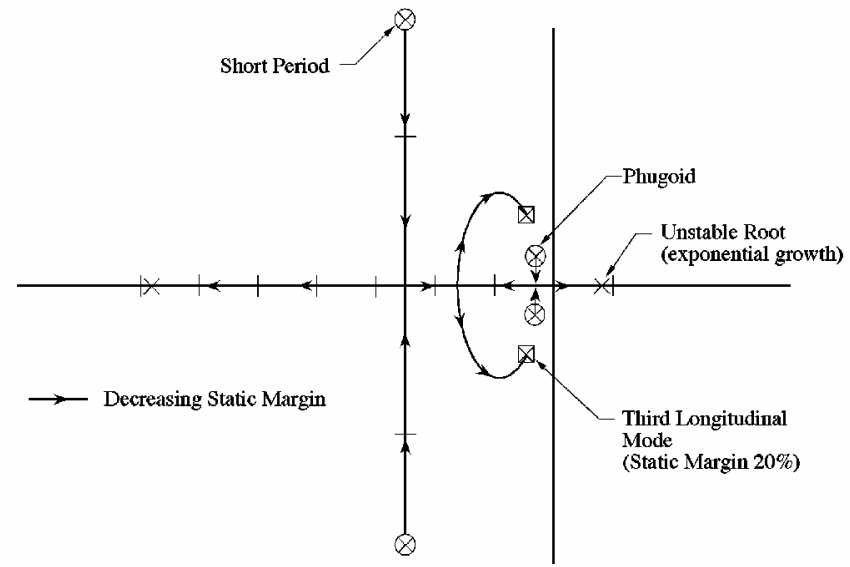

Fig. A1 Locus of roots as the static margin is varied from the initial stable condition $\otimes$ to an unstable condition corresponding to that of the 1903 Flyer.

the flight characteristics of the Wright Flyers provides the context within which minimal modifications of the original geometry are accomplished.

\section{Appendix: Migration of Roots for Decreasing Static Margin}

It seems that only Etkin $^{37}$ (pp. 352 ff) has previously examined quantitatively the influence of negative static margin on the longitudinal dynamics of a rigid aircraft. The locus of roots can be constructed using available software for feedback control by taking the gain equal to the static margin. Figure A1 illustrates the migration of the roots representing the phugoid and short-period oscillations of a stable aircraft (identified by $\otimes$ ) to the roots for the degenerate short-period motion and the low-frequency "third longitudinal mode as the static margin increases." The final locations of the roots indicated by $\times$ correspond to the open-loop roots for the root locus plot in Fig. 16.

\section{Acknowledgments}

I am especially indebted to Henry Jex for all he has taught me about aerodynamics, flight mechanics, and control during our association for more than 20 years in the AIAA Wright Flyer Project. Only the extraordinary efforts of the members of the project, particularly Chairman Jack Cherne and Deputy Chairman Howard Marx, made possible the construction and wind-tunnel tests of the fullscale Wright Flyer in March 1999. The test results, and those obtained from tests of the subscale models, form the basis for analyzing the special flight mechanics of the 1903 Flyer. I have benefited greatly from many private discussions and from exchanges of e-mail messages with correspondents otherwise unknown to me. Figures 13-15 and 18-20 were prepared by Antonis Papachristodoulou. Portions of this paper appeared in the Proceedings of the FortyFifth Annual Symposium of the Society of Experimental Test Pilots (September 2001). I thank Melinda Kirk for her enormous efforts preparing the final typed and formatted version of the manuscript.

\section{References}

${ }^{1}$ Gibbs-Smith, C. H., Sir George Cayley's Aeronautics 1796-1855, His Majesty's Stationery Office, London, 1962.

${ }^{2}$ Cayley, G. G., "On Aerial Navigation,” Nickolson's Journal, Vol. 24, Pt. 1, 1810, pp. 164-174.

${ }^{3}$ Cayley, G. G., "On Aerial Navigation," Nickolson's Journal, Vol. 25, Pt. 2, 1810, pp. 81-87.

${ }^{4}$ Cayley, G. G., "On Aerial Navigation,” Nickolson's Journal, Vol. 25, Pt. 3, 1810, pp. 161-169.

${ }^{5}$ Pénaud, A., "Aeroplane Automoteur; Équilibre Automatique," L'Aeronaut, Vol. 5, 1872, pp. 2-9.

${ }^{6}$ Kutta, W. M., "Auftribshrafte in Strömanden Flussigheiten, " Illustrierte Aeronautische Mitteilungen, Vol. 6, 1902, pp. 133-135.

${ }^{7}$ Lilienthal, O., Der Vogelflug als Grundlage der Fleigekunst, R. Gaertners, Verlagsbuchhandlung, Berlin, 1889; translated by Isenthal, I. W., Birdflight as the Basis of Aviation, Longmens and Green, London, 1911.
${ }^{8}$ Chanute, O., Progress in Flying Machines, 1894, reprint, Lorenz and Herweg, Long Beach, CA, 1976.

${ }^{9}$ Spearman, A. D., John Joseph Montgomery, 1858-1911: Father of Basic Flying, Univ. of Santa Clara, Santa Clara, CA, 1967.

${ }^{10}$ Anderson, J. D., A History of Aerodynamics, Cambridge Univ. Press, Cambridge, England, U.K, 1997.

${ }^{11}$ Combs, H., Kill Devil Hill, Houghton Mifflin, Boston, 1979.

${ }^{12}$ Crouch, T., A Dream of Wings: Americans and the Airplane 1875-1905, W. W. Norton, New York, 1981.

${ }^{13}$ Crouch, T., The Bishop's Boys, W. W. Norton, New York, 1989.

${ }^{14}$ Culick, F. E. C., "Origins of the First Powered, Man-Carrying Airplane," Scientific American, Vol. 241, No. 1, 1979, p. 86.

${ }^{15}$ Culick, F. E. C., and Dunmore, S., On Great White Wings, Hyperion, New York, 2001.

${ }^{16}$ Gibbs-Smith, C. H., The Wright Brothers, Science Museum, Her Majesty's Stationery Office, London, 1963.

${ }^{17}$ Gibbs-Smith, C. H., Aviation: An Historical Survey from Its Origins to the End of World War II, Her Majesty's Stationery Office, London, 1970.

${ }^{18}$ Hooven, F., "The Wright Brothers' Flight Control System," Scientific American, Vol. 240, No. 1, 1978.

${ }^{19}$ Howard, F., Wilbur and Orville, Alfred A. Knopf, New York, 1987.

${ }^{20}$ Jakab, P. L., Visions of a Flying Machine, Smithsonian Inst. Press, Washington, DC, 1990.

${ }^{21}$ Kelly, F. C., The Wright Brothers, Ballantine, New York, 1943.

${ }^{22}$ Walsh, J. E., One Day at Kitty Hawk: The Untold Story of the Wright Brothers and the Airplane, Crowell, New York, 1975.

${ }^{23}$ Wolko, H., The Wright Flyer-An Engineering Perspective, Smithsonian Inst. Press, Washington, DC, 1987.

${ }^{24} \mathrm{McF}$ arland, M. W, (ed.), The Papers of Wilbur and Orville Wright, McGraw-Hill, New York, 1953, pp. 38, 469, 470, 503, 520, 521, 721.

${ }^{25}$ Engler, N., "Resurrecting the 1899 Wright Kite," World War I Aero., 1999.

${ }^{26}$ Engler, N., "The Wrights 1902 Glider-Its Construction, Design and Flight Characteristics," AIAA Paper 2001-3384, Aug. 2001.

${ }^{27}$ Wright, W., "Some Aeronautical Experiments," Journal of the Western Society of Engineers," Vol. 1, Dec. 1901, pp. 99-118.

${ }^{28}$ Chanute, O., "Artificial Flight," Pocket-Book of Aeronautics, Whittaker, London, 1907.

${ }^{29}$ Moedebeck, H. W., Pocket-Book of Aeronautics, Whittaker, London, 1907.

30“Aerodynamic Characteristics of Airfoils” NACA TR 93, 1920.

${ }^{31}$ Jacobs, E. N., Ward, E. K., and Pinkerton, R. M., "The Characteristics of 78 Related Airfoil Sections from Tests in the Variable Density Wind Tunnel," NACA Rept. 460, 1932.

32،"Engineering Sciences Data," Aeronautical Series, Aeronautical SubSeries, Item 70015, Royal Aeronautical Society, 1970.

${ }^{33}$ von Mises, R., "Fur Theories des Tragflächenauftriebes" ZAMM, Vol. 11 , No. 5 , 1920 , pp. $68-73,87-89$

${ }^{34}$ Tchaplygin, S. A., "On a General Theory of the Monoplane Wing," Memorandum Superior War Council for Publications, 1922; translated by Garbell, M. A., Selected Works, Garbell Research Foundation, San Francisco, 1956.

${ }^{35}$ Bryan, G. H., and Williams, W. E., "The Longitudinal Stability of Gliders," Proceedings of the Royal Society of London, Vol. 73, 1904, pp. 100116.

${ }^{36}$ Bryan, G. H., Stability in Aviation, Macmillan, London, 1911.

${ }^{37}$ Etkin, B., Dynamics of Atmospheric Flight, Wiley, 1972.

${ }^{38}$ Perkins, C. D., and Hage, R. E., Airplane Performance Stability and Control, Wiley, New York, 1949.

${ }^{39}$ Bettes, W. H., and Culick, F. E. C., "Report on Wind Tunnel Tests of a 1/6-Scale Model of the 1903 Wright Flyer," Guggenheim Aeronautical Lab., GALCIT Rept. 1034, California Inst. of Technology, Pasadena, CA, 1982.

${ }^{40}$ Turnbull,W. R., "Researches on the Forms and Stability of Aeroplanes," Physical Review, Vol. 24, No. 3, 1907, pp. 133-135.

${ }^{41}$ Culick, F. E. C., and Jex, H., "Aerodynamics Stability and Control of the 1903 Wright Flyer," Proceeding so the Symposium on the 80th Anniversary of the Wright Flyer, Smithsonian Inst. Press, Washington, DC, Dec. 1987, 1983.

${ }^{42}$ Kochersberger, K., Ash, R., Sandusky, R., and Hyde, K., "An Evaluation of the Wright 1901 Glider Using Full-Scale Wind Tunnel Data," AIAA Paper 2002-1134, Jan. 2002.

${ }^{43}$ Jex, H., and Culick, F. E. C., "Flight Control Dynamics of the 1903 Wright Flyer," AIAA Paper 85-1804, Aug. 1985.

${ }^{44}$ Hegland, T., 1903 Wright Flyer 1/8-Scale Model Wind Tunnel Aerodynamic Data," Northrop Corp., 1982.

${ }^{45}$ Jex, H. R., Grimm, R., Latz, J., and Hange, C., "Full-Scale 1903 Wright Flyer Wind Tunnel Test Results from the NASA Ames Research Center," AIAA Paper 2000-0512, Jan. 2000. 
${ }^{46}$ McRuer, D., Ashkenas, I., and Graham, D., Aircraft Dynamics and Automatic Control, Princeton Univ. Press, Princeton, NJ, 1973.

${ }^{47}$ Papachristodoulou, A. N., and Culick, F. E. C., "Flight Mechanics of the Wright Aircraft, 1903-1912," AIAA Paper 2003-0097, 2003.

${ }^{48}$ Wald, Q., The Wright Brothers as Engineers, an Appraisal, published by the author, 1999 .

49 "A Limited Handling Qualities Evaluation of an In-Flight Simulation of the 2003 Wright Flyer," Air Force Flight Test Center, Rept. AFFTC-TIM01-07, U.S. Air Force Test Pilot School, Edwards AFB, CA, April 2001.

${ }^{50}$ Renstrom, A. G., Wilbur and Orville Wright-A Chronology Commem- orating the Hundredth Anniversary of the Birth of Orville Wright, Library of Congress, Washington, DC, 1975.

${ }^{51}$ Ferber, F., L'Aviation: Ses Débuts-Son Dévelopment, Berger-Levrault, Paris, 1908.

${ }^{52}$ Crouch, T., Blériot XI: The Story of a Classic Aircraft, Smithsonian Inst. Press, Washington, DC, 1982.

53 "Pilots: Ken Kellett," AOPA Magazine, Feb. 1989, p. 124.

G. M. Faeth Former Editor-in-Chief 